\title{
Padrão Morfológico e Características Oclusais De Crianças Respiradoras Bucais Após CiruRgia Para Hipertrofia De Tonsilas
}

\author{
Tese apresentada à Faculdade de Odontologia de \\ Ribeirão Preto da Universidade de São Paulo para \\ obtenção do Título de Doutor no Programa de Pós- \\ Graduação em Odontopediatria.
}

Orientadora: Profa. Dra. Mírian Aiko Nakane Matsumoto

Ribeirão Preto

2009 
Mattar, Sara Elisa Medina,

Padrão morfológico e características oclusais de crianças respiradoras bucais após cirurgia para hipertrofia de tonsilas. Ribeirão Preto, 2009.

75 p. : il. ; $30 \mathrm{~cm}$

Tese de Doutorado, apresentada à Faculdade de Odontologia de Ribeirão Preto/USP. Área de concentração: Odontopediatria.

Orientadora: Matsumoto, Mírian Aiko Nakane

1. Respirador bucal. 2. Adenotonsilectomia,. 3. Hipertrofia de tonsilas. 4 Desenvolvimento dentofacial. 5. Padrão respiratório pósoperatório. 


\title{
Padrão Morfológico E CaRacterísticas OCLUSAIS De Crianças Respiradoras Bucais Após Cirurgia \\ Para Hipertrofia De Tonsilas
}

\begin{abstract}
Tese apresentada à Faculdade de Odontologia de Ribeirão Preto da Universidade de São Paulo para obtenção do Título de Doutor no Programa de Pós-Graduação em Odontopediatria.
\end{abstract}

Data da defesa:

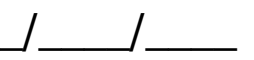

\section{Banca Examinadora}

Prof. Dr.

Julgamento: Assinatura:

Prof. Dr.

Julgamento: Assinatura:

Prof. Dr.

Julgamento: Assinatura:

Prof. Dr.

Julgamento: Assinatura:

Prof. Dr.

Julgamento: Assinatura: 
A todas as criancas, que com tanta garra, desde tão pequenas, enfrentam as adversidades da vida. Vocês que me fazem rir e ás vezes chorar com suas historias, mas acima de tudo, servem de inspiração constante para que a cada dia, eu possa ser uma pessoa e profissional um pouco melhor. Muito obrigada! 


\section{Dedico esse Trabalho}

Aos meus pais, Amir Mattar e Walkiria Medina Coeli Mattar, pelo princípio de "tudo". Pela demonstração de uma vida simples, mas sólida de princípios. Todas as conquistas que tive e ainda terei dedico a vocês!

Ao Carlos Augusto Tormin,por todo amor; carinho e apoio tão essenciais na realização desta tese, estando ao meu lado ora como escudo ora como ancora. Obrigada pela história que estamos construindo juntos! 


\section{Agradecimentos EspeCiaIS}

A minha orientadora, Profa. Dra. Mirian Aiko Nakane Matsumoto, professora do Departamento de Clínica Infantil, Odontologia Preventiva e Social da Faculdade de Odontologia de Ribeirão Preto/USP, pela confiança em meu trabalho e pela oportunidade para meu crescimento. A nossa convivência faz com que eu a admire mais como pessoa e profissional. Fica aqui registrada minha extrema gratidão! Obrigada.

À Profa. Dra. Gisele Faria, Pós- doutoranda do Departamento de Patologia da Faculdade de Medicina de Ribeirão Preto - USP pela grande contribuição, paciência e amizade no desenvolvimento deste trabalho! Obrigada. 


\section{Meus Sinceros Agradecimentos}

Aos professores Beatriz Medina Coeli Barbosa, lale Teixeira Bomtempo e Mara Lúcia Bonfim pela colaboração e amizade.

Aos colegas cirurgiões-dentista Richard Honorato de Oliveira e Patrícia Amato pela colaboração na realização deste trabalho.

Aos colegas e funcionários do Centro Odontológico Especializado, em especial Adriana Farneze e Simara Cacciari, por desfrutarmos juntos a arte da vida na busca de sermos profissionais mais humanos e de qualidade.

Ás professoras de Odontopediatria da Clínica Integrada da Universidade de Uberaba, pelo companheirismo, carinho e apoio tão essenciais na concretização de mais uma etapa.

Aos amigos de Uberaba e Ribeirão Preto, que acompanharam esta conquista. Amizade é como estrelas, não às vemos sempre, mas sabemos que existem. Agradeço por fazerem parte da minha vida.

Aos meus familiares, que sempre me acompanham com entusiasmo na busca de meus ideais e pela presença constante nos momentos de tristeza e alegria.

A Marina e Fernanda, pelo carinho e apoio!

Ao Dr.Celso Charuri que me faz acreditar num mundo cada vez melhor! 


\section{AgRadecimentos}

À Universidade de São Paulo.

À Faculdade de Odontologia de Ribeirão Preto/USP.

À Comissão de Pós-Graduação da Faculdade de Odontologia de Ribeirão Preto/USP, na pessoa da atual Presidente Profa. Dra. Léa Assed Bezerra da Silva.

À Faculdade de Odontologia da Universidade de Uberaba na pessoa do Reitor Marcelo Palmério.

Aos professores da Disciplina de Odontopediatria do Departamento de Clínica Infantil, Odontologia Preventiva e Social, da Faculdade de Odontologia de Ribeirão Preto/USP, Profa. Dra. Sada Assed. Profa. Dra. Aldevina Campos de Freitas, Profa. Dra. Léa Assed Bezerra da Silva, Prof. Dr. Paulo Nelson Filho, Profa. Dra. Kranya Victoria Díaz Serrano, Profa. Dra. Maria Cristina Borsatto, Profa. Dra. Raquel Assed Bezerra da Silva, por toda a atenção e amizade.

Aos professores da Disciplina de Ortodontia do Departamento de Clínica Infantil, Odontologia Preventiva e Social, da Faculdade de Odontologia de Ribeirão Preto/USP, Prof. Dr. Adilson Thomazinho, Prof. Dr. Tarcísio Lima Ferreira, Profa. Dra. Mirian Aiko Nakane Matsumoto e Profa. Dra. Maria Bernadete Sasso Stuani, pelo apoio e agradável convivência.

Aos colegas do Curso de Pós-Graduação em Odontopediatria da Faculdade de Odontologia de Ribeirão Preto/USP, Alexandra Mussolino de Queiroz Francisco Wanderley Garcia de Paula e Silva, Valéria Pontelli Navarro Tedeschi, Marta Estela Saravia, Maria Angélica Hueb de Menezes Oliveira, Soraia Monique Fiorati Aguiar e Raquel Assed Bezerra da Silva, pela agradável convivência. Muito obrigada pelo apoio, carinho e amizade que conquistamos juntos.

Às professoras do Programa de Pós-Graduação da Faculdade de Odontologia de Ribeirão Preto/USP, e da Faculdade de Medicina de Ribeirão Preto/USP Profa. Dra. Kranya Victoria Díaz Serrano, Profa. Dra. Fabiana Pereira Valera, obrigada pela valiosa contribuição no exame de qualificação.

Ao Departamento de Morfologia, Estomatologia e Fisiologia, nas pessoas do Dr. Plauto Watanabe e Regina Célia Rodrigues de Souza. Em especial ao Tarciso José Rodrigues Júnior por seu trabalho técnico, paciência e ajuda.

A Dra. Wilma T. Anselmo-Lima, Dra. Fabiana Pereira Valera e equipe pela atuacão Otorrinolaringológica, trabalho e cooperação, sem os quais esta pesquisa não seria possivel.

Aos funcionários do Departamento de Clínica Infantil, Odontologia Preventiva e Social, da Faculdade de Odontologia de Ribeirão Preto/USP, em especial Micheli Cristina Leite Rovanholo e Rejane Gomes Cavalheiro Mazer, pela agradável convivência e colaboração. A boa vontade e o carinho de vocês serão sempre lembrados.

Às funcionárias da Secção de Pós-Graduação da Faculdade de Odontologia de Ribeirão Preto/USP, Isabel Cristina Galino Sola e Regiane Cristina Moi Sacilotto, pela dedicação e carinho dispensados a todos os alunos de pós-graduação.

Ao Clic foto \& Video e Rosemary Alves, pela diagramação e impressão desse trabalho.

À todos que, de alguma forma, contribuíram para a concretização dessa pesquisa. 


\section{Lista De Figuras}

Figura 1 - Esquema das características anatômicas avaliadas na radiografia da coluna aérea segundo método de Cohen e Konak (1985).

Figura 2 - Modelos de estudo em oclusão para avaliação da relação ântero-posterior de caninos decíduos e plano terminal dos segundos molares decíduos.

Figura 3 -

Plano terminal dos segundos molares decíduos: A) reto;

B) mesial;

C) distal (McDonald e Avery, 1995).

Figura 4 - Mordida cruzada posterior

Figura 5 - Mordida aberta anterior.

Figura 6 - Vista lateral dos modelos de estudo ocluídos com distâncias de overjet.

Figura 7 - Vista oclusal da arcada superior com distâncias intercaninos e intermolares.

Figura 8 - Traçado das estruturas anatômicas dentofaciais, tecidos moles e pontos cefalométricos utilizados no estudo. Cefalograma ilustrando as medidas cefalométricas angulares...

Figura 9 - $\quad$ Cefalograma ilustrando as medidas cefalométricas lineares......

Figura 10 - Porcentagem de indivíduos segundo ausência e presença de mordida aberta $(A)$, mordida cruzada(B), e em relação ao overbite (C), relação ântero-posterior de caninos decíduos direito e esquerdo (D) e plano terminal dos segundos molares decíduos direito e esquerdo (E) no tempo T1 nos grupos RB e RN.

Figura 11 - Porcentagem de indivíduos segundo ausência e presença de mordida aberta (A), mordida cruzada (B), e em relação ao overbite (C), relação ântero-posterior de caninos decíduos direito e esquerdo (D) e plano terminal dos segundos molares decíduos direito e esquerdo (E) no tempo T2 nos grupos RB e RN.

Figura 12 - Comparação da porcentagem de indivíduos segundo presença ou ausência de mordida aberta (A e B) e mordida cruzada (C e D) entre os tempos T1 e T2 nos grupos RB e RN

Figura 13 - Comparação da porcentagem de indivíduos em relação ao overbite (A e B), relação ântero-posterior de caninos decíduos direito e esquerdo ( $C$ e $D$ ) e plano terminal dos segundos molares decíduos direito e esquerdo (E e F) entre os tempos T1 e T2 nos grupos RB e RN. 


\section{LISTA DE TABELAS}

Tabela 1 - Comparação das medidas cefalométricas entre grupos RB e RN no tempo T1, por meio do teste $t$ de Student.

Tabela 2 - Comparação das medidas cefalométricas entre grupos RB e RN no tempo T2 por meio do teste $t$ de Student.

Tabela 3 - Comparação das medidas cefalométricas entre os tempos T1 e $\mathrm{T} 2$ nos grupos RB e RN, por meio do teste t pareado.

Tabela 4 - Comparação da variação das medidas cefalométricas (T2-T1) entre os grupos RB e RN, por meio do teste t de Student

Tabela 5 - Comparação das medidas oclusais entre os grupos RB e RN no tempo T1 por meio do teste $t$ de Student.

Tabela 6 - Comparação das medidas oclusais entre os grupos RB e RN no tempo $\mathrm{T} 2$ por meio do teste $\mathrm{t}$ de Student

Tabela 7 - Comparação das medidas oclusais entre os tempos T1 e T2 nos grupos RB e RN, por meio do teste t pareado.

Tabela 8 - Comparação da variação das medidas oclusais (T2-T1) entre os grupos RB e RN, por meio do teste $t$ de Student.

Tabela 9 - Comparação das características oclusais entre os grupos RB e RN no tempo T1, por meio do teste quiquadrado e Mann Whitney.

Tabela 10 - Comparação das características oclusais entre os grupos RB e RN no tempo T2, por meio do teste quiquadrado e Mann Whitney

Tabela 11 - Comparação das características oclusais entre os tempos T1 e T2 dentro de cada grupo, por meio do teste Mac-Nemar, Wilcoxon e Quiquadrado.

Tabela 12 - Comparação da variação das características oclusais (T2-T1) entre os grupos RB e RN, por meio do teste quiquadrado e Mann Whitney 


\section{RESUMO}

MATTAR, SEM. Padrão morfológico e características oclusais de crianças respiradoras bucais após cirurgia para hipertrofia de tonsilas \{tese\}. Ribeirão Preto: FORP - Universidade de São Paulo; 2009.

Alterações morfológicas e dentofaciais têm sido repetidamente atribuídas ao impedimento da função naso-respiratória devido à hipertrofia de tonsilas faríngea e palatinas. O objetivo da presente investigação foi avaliar o padrão esquelético e características oclusais de crianças respiradoras bucais antes (T1) e em média 28 meses após (T2) serem submetidas à cirurgia para remoção de tonsilas hipertrofiadas, comparando com crianças respiradoras nasais. O grupo experimental foi composto de 33 crianças respiradoras bucais (RB) e o grupo controle, de 32 crianças respiradoras nasais (RN). Os exames ortodônticos (radiografia cefalométrica e modelos de estudo) foram realizados em ambos os grupos nos tempos T1 e T2. Na comparação entre os grupos, os resultados permitiram concluir que os respiradores bucais apresentaram maior inclinação do plano mandibular em relação à base craniana e ao plano palatal (SN.GoGn; PP.PM); ângulo goníaco mais obtuso (ArGo.GoMe); tendência ao tipo morfológico dolicofacial (BaN.PtGn); altura do ramo da mandíbula (Ar-Go) e altura posterior da face (S-Go) diminuídas; maior número de mordidas cruzadas e menor distância intermolares. Em T2, o padrão morfológico predominante da face foi mesofacial no grupo RN e dolicofacial no grupo RB; o overbite foi normal nos RB e profundo nos RN e o overjet apresentou-se maior nos RB. Em relação à mordida aberta, mordida cruzada, relação de caninos, plano terminal dos segundos molares decíduos e distância intercaninos e intermolares houve semelhança entre os grupos RB e RN. Ao analisar cada grupo separadamente, verificou-se que, vinte e oito meses após a cirurgia, nos RB, houve alteração na direção do crescimento da face e inclinação do plano mandibular no sentido anti-horário, com diminuição dos valores de SN.GoGn, PP.PM, SNGn, ArGo.GoMe e aumento de BaN.PtGn. Em ambos os grupos houve crescimento vertical anterior e posterior da face, evidenciado pelo aumento das medidas verticais lineares ( $\mathrm{N}-\mathrm{Me}, \mathrm{N}-\mathrm{ENA}$, ENA-Me, S-Go, S-Ar, Ar- Go). O plano terminal dos segundos molares decíduos modificou-se de reto para degrau mesial nos dois grupos; o overbite alterou de negativo para normal no grupo RB e tornou-se profundo, no grupo RN. No presente estudo, a desobstrução das vias aéreas através da remoção cirúrgica das tonsilas faríngea e/ou palatinas em crianças entre 3 e 6 anos de idade, resgatou o padrão de crescimento normal para esses pacientes respiradores bucais, mostrando resultados excelentes sobre as características oclusais e esqueléticas.

Palavras-chave: respirador bucal, adenotonsilectomia, hipertrofia de tonsilas, desenvolvimento dentofacial, padrão respiratório pós-operatório. 


\section{SUMMARY}

MATTAR, SEM. Morphological pattern and occlusal characteristics of the mouth-breathing children after surgery for tonsils hypertrophy. \{Thesis\}. Ribeirão Preto: FORP - Universidade de São Paulo; 2009.

Morphological and dentofacial abnormalities have been attributed to respiratory obstruction caused by adenoid and tonsils hypertrophy. The objective of the present study was to evaluate the skeletal patterns and occlusal characteristics in mouthbreathing children before (T1) and a mean of 28 months after (T2) they have been were submitted to surgery for tonsils hypertrophy, compared with those of nosebreathing children. The experimental group was composed of 33 mouth-breathing children (MB) and the control group, 32 nose-breathing children (NB). Orthodontic examinations (cephalometric radiography and study models) were performed on both groups at the times T1 and T2. After comparisons between the groups, it could be concluded that the MB presented greater inclination of the mandibular plane in relation to the cranial base and palatal plane (SN.GoGn, PP.PM); more obtuse gonial angle (ArGo.GoMe); tendency towards the dolicofacial pattern (BaN.PtGn); reduced height of the mandibular ramus (Ar-Go) and lower posterior height of the face (S-Go); higher frequency of crossbite and smaller intermolar distance. After surgery (T2), the predominant morphological pattern of the face was mesofacial in NB and dolicofacial in $\mathrm{MB}$; the overbite was normal in MB and deep in NB; the overjet was greater in MB; the two groups were similar in relation to open bite, crossbite, the antero-posterior canines relationship and the second deciduous molars terminal plane, and the intercanine and intermolar distances. Separate analysis on each group showed that, 28 months after surgery, the MB presented an counterclockwise rotation of the mandible, smaller SN.GoGn, PP.PM, SNGn and ArGo.GoMe values and larger BaN.PtGn value. In both groups, there was anterior and posterior vertical growth of the face, with increase in the linear vertical measurements (N-Me, N-ENA, ENA-Me, S-Go, S-Ar and Ar-Go). The second deciduous molars terminal plane changed from straight to mesial, in both groups; the overbite changed from negative to normal in MB and it became deep in NB. In the present study, the surgery for tonsils hypertrophy in children aged 3 to 6 years restored the normal growth pattern for these mouth-breathing patients, with excellent results regarding occlusal and skeletal characteristics.

Key-words: mouth breathing, adenotonsillectomy, tonsil hypertrophy, dentofacial development, post-operative respiratory pattern 


\section{SUMÁRIO}

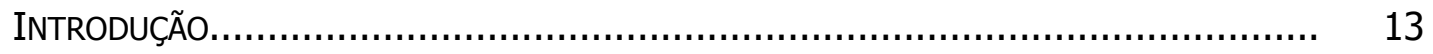

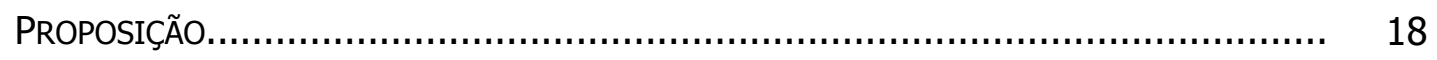

MATERIAL E MÉTODOS................................................................ 20

1) Seleção da amostra.................................................................... 21

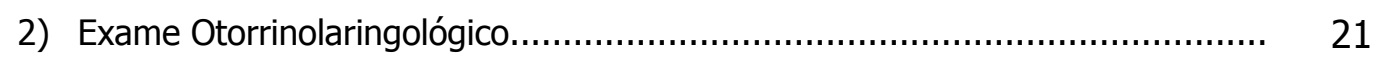

3) Avaliação ortodôntica................................................................. 23

4) Avaliação pós-cirurgica............................................................ 32

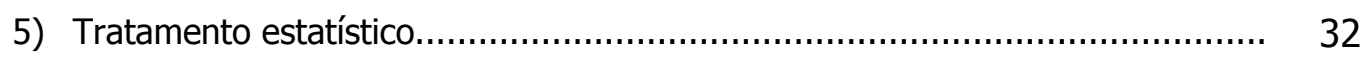

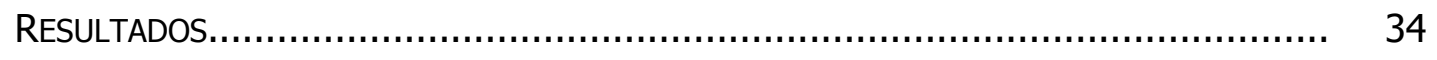

1) Medidas cefalométricas........................................................... 35

2) Características oclusais............................................................. 38

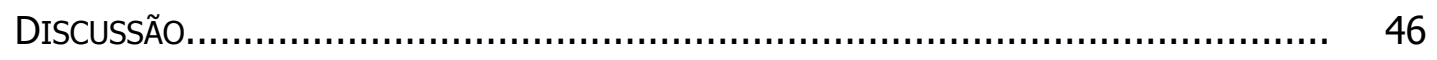

1) Avaliação das medidas cefalométricas............................................ 47

2) Avaliação das características oclusais.................................................... 54

CONCLUSÃO......................................................................... 59

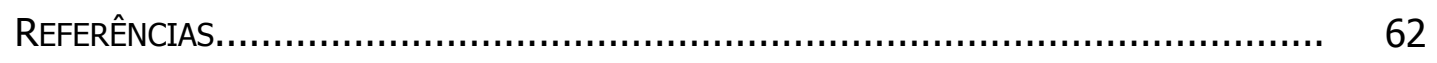

ANEXOS............................................................................. 70 
2 


\section{INTRODUÇÃO}

A obstrução nasal é conhecida por representar um importante fator etiológico das deformidades morfológicas, dento-faciais, alterações posturais e miofuncionais durante a fase de crescimento dos indivíduos (Cheng et al., 1988; Valera et al., 2006; Cuccia et al., 2008; Cattoni et al., 2007; Peltomäki, 2007).

$\mathrm{Na}$ grande maioria das vezes existe uma causa definida de respiração bucal. A hipertrofia adenoamigdaliana e rinite alérgica são as mais freqüentes, como já descritas por vários autores (Klein, 1986; Di Francesco, 1999; Motonaga et al., 2000; Mocellin et al., 2000; Greenfeld et al., 2003; Cattoni et al., 2007). É comum a hipertrofia da tonsila faríngea estar associada com rinite alérgica, exacerbando os sintomas respiratórios (Lima et al., 2005).

Considerando a doutrina das matrizes funcionais, se houver obstrução na área naso e ororespiratória, muitas influências podem ser exercidas na direção de crescimento das estruturas do esqueleto da face, pela necessidade de continuar reposturando os tecidos moles e as estruturas esqueletais (Subtelny, 1975; Lee et al., 2007).

Em 1968, Ricketts descreveu com detalhes as características dos indivíduos portadores de Obstrução Respiratória. As alterações morfológicas e dentofaciais têm sido repetidamente atribuídas ao impedimento da função naso-respiratória por vários autores (Linder-Aronson, 1970; Schendel et al., 1976; Vig et al., 1981; McNamara, 1981; Woodside et al., 1991; Linder-Aronson et al., 1993; Oulis et al., 1994; Kawashima, 2002; Zettergren-Wijk et al., 2006).

Os estudos mostram distúrbios de posição mandibular no sentido ântero-posterior, divergência aumentada dos planos horizontais, mudança na direção de crescimento da mandíbula, aumento nos ângulos craniomandibulares, alteração nas alturas verticais anteriores e posteriores da face, e assimetrias responsáveis pelo estreitamento maxilar. No exame ortodôntico, por meio dos exames clínicos, extra e intra-oral e análise de modelos, pode-se evidenciar também o comprometimento da musculatura facial com hipotonia, ausência de selamento labial, alteração na postura da cabeça e coluna cervical, narinas estreitas, olheiras, face alongada com terço inferior mais evidente, gengivite marginal nos incisivos, estreitamento da arcada superior e/ou inferior, palato em ogiva, mordida aberta anterior, mordida cruzada posterior, alteração na posição dos incisivos, distância entre molares e caninos alterada, relação distal de molares e overjet aumentado (Linder - Aronson, 1970, 1979; 
Bresolin et al., 1983, 1984; Moreira, 1989; Ung et al., 1990; Warren, 1990; Hulcrantz et al., 1991; Aragão, 1991; Tourné, 1991; Gross et al., 1994; Oulis et al., 1994; Tourne e Schweiger, 1996; Zucconi et al., 1999; Weider et al., 2003; Arun et al., 2003; Lessa et al., 2005; Sousa et al., 2005; Peltomaki, 2007; Góis et al., 2008).

Behlfelt e colaboradores, em 1990, verificaram que postura estendida da cabeça, baixa posição do osso hióide, e postura ântero-inferior da língua, parecem ter muitas associações com a necessidade de manter o espaço orofaringeano com passagem livre em crianças com tonsilas aumentadas. Há uma dependência na relação entre: modo respiratório, postura da cabeça, postura mandibular, atividade postural em específicos músculos mastigatórios e do pescoço e a morfologia craniofacial em indivíduos em crescimento que apresentam obstrução nasal (Hiyama et al., 2003; Ribeiro e Marchiori, 2004; Cuccia et al., 2008).

Yi et al., em 2003, concluiram que as alterações posturais no corpo mais comuns são: protrusão de ombros, anteversão de pelve, protrusão de cabeça, escápulas aladas, hiperlordose lombar, retificação dorsal e pés planos. Ocorre uma adaptação postural músculo-esquelética frente à respiração oral, associada ao padrão postural hipotônico. Ao longo do tempo, o respirador bucal pode apresentar distúrbios do reflexo nasopulmonar, com prejuízo da expansão torácica e da ventilação alvéolopulmonar (Arrarte et al., 2007) e também complicações cardiorespiratórias.

Em alguns estudos, os resultados parecem ser inconclusivos, devido à metodologia aplicada para determinar o padrão respiratório. Segundo O'Ryan et al. (1982), seria extremamente necessário mensurar a quantidade relativa de respiração oral versus nasal antes que as vias aéreas obstruídas pudessem ser implicadas como um fator etiológico significante no desenvolvimento de alguma espécie de deformidade dentofacial. Porém, outros fatores determinantes devem ser considerados. Existem crianças com padrões faciais e musculares hereditários (apresentando faces longas e maior estreitamento das vias aéreas faringeanas superiores) mais predispostos à obstrução nasorespiratória (Subtelny, 1980). Conseqüentemente, esses indivíduos seriam mais facilmente afetados com mudanças no padrão respiratório, acarretando maiores seqüelas ao Sistema Estomatognático (Hiyama et al., 2003).

Outros autores (Kluemper et al., 1995; Nowak e Warren, 2000) não aceitam a afirmação de que morfologia facial e modo respiratório são intimamente relacionados, baseados no fato que, nas suas pesquisas, as metodologias utilizadas foram estáveis e confiáveis. Klein (1986) não encontrou nenhuma prova conclusiva que a obstrução da respiração altera o crescimento e desenvolvimento facial. Bianchini et 
al. (2007) não conseguiram comprovar a existência de uma relação entre a respiração oral e o tipo facial. Desta forma, as pesquisas sobre o tema da respiração bucal ainda não se esgotaram.

Alguns pesquisadores acompanham em estudos transversais e longitudinais, as mudanças observadas após cirurgia de remoção das tonsilas palatinas (tonsilectomia) e tonsila faríngea (adenoidectomia), ou ambas (adenotonsilectomia) em crianças e adultos, e laser-tonsilotomia (Zuconni et al., 1999; Greenfeld et al., 2003; Guileminault et al., 2004; Unkel et al., 2005; Chaux et al., 2008). Os achados mostram que o alívio na obstrução das vias aéreas num individuo em crescimento, favorece o desenvolvimento craniofacial, dentofacial, postural e miofuncional (Linder- Aronson et al., 1986, 1993; Behlfelt, 1990; Woodside et al., 1991), levando até a "normalização" da oclusão em crianças (Linder-Aronson, 1974; Hulcrantz et al., 1991; Weider et al., 2003; Greenfeld et al., 2003; Peltomäki, 2007). Conceituados trabalhos mostram que a mandíbula cresce numa direção mais horizontal (Behlfelt et al., 1990; Agren et al., 1998), havendo melhora na inclinação dos incisivos superiores e inferiores, nas alturas faciais verticais anteriores e posteriores, na largura do arco superior, correção de mordidas abertas e mordidas cruzadas, alteração na profundidade sagital do espaço nasofaríngeo e da inclinação do plano mandibular (Linder-Aronson, 1979; Hulcrantz et al., 1991; Agren et al., 1998; Weider et al., 2003).

No estudo de Zettergreen-Wijk et al. (2006), em comparação com os controles, inicialmente as crianças exibiram mandíbula mais inclinada posteriormente e maxila inclinada mais anteriormente, altura facial ântero-inferior aumentada, base craniana anterior encurtada, retroinclinação dos incisivos superiores e inferiores, redução do espaço das vias aéreas e nariz menos pronunciado. Cinco anos póstratamento cirúrgico, não houve diferenças estatísticas significantes entre os grupos, exceto para as medidas da base anterior do crânio e nariz que ainda eram menores no grupo dos pacientes respiradores bucais. A melhora do estatus miofuncional (postura facial, tonicidade, mastigação, deglutição, e respiração) também foi observada em crianças correlacionando padrões pré e pós cirúrgico, durante um período de 24 meses (Valera et al., 2006), pois ocorre adequação dos padrões funcionais do Sistema Estomatognático (Junqueira et al., 2002).

Cooper (1989), Principato (1991), Mocellin et al. (2000) e Bruni (2008), indicaram a necessidade de intervenção o mais precoce possível para possibilitar a respiração nasal. À partir dos 3 anos de idade a maioria das alterações são visíveis, mas são mais comumente detectadas à partir dos 5 anos. O impacto deletério das 
conseqüências da obstrução no desenvolvimento craniofacial atinge seu ápice na puberdade. Conseqüentemente, a oportunidade para intervenção com sucesso é limitada (Principato, 1991). Após as crianças entrarem no estágio de dentição mista (mais de 6 anos), torna-se difícil conseguir uma correção ortodôntica espontânea depois da tonsilectomia (Hulcrantz et al., 1991).

Mesmo partindo do pressuposto que, existe relação entre obstrução das vias aéreas superiores e alteração de crescimento e desenvolvimento das estruturas orofaciais, ainda torna-se importante saber quando o tratamento tem uma resposta positiva recuperando as seqüelas deixadas e permitindo que o indivíduo se desenvolva normalmente. Ainda não se tem conhecimento de qual a idade ideal para realizar o tratamento cirúrgico, considerado um tratamento mais radical, para recuperar o padrão respiratório, e reabilitar espontaneamente as alterações funcionais, esqueléticas, miofuncionais e posturais. 


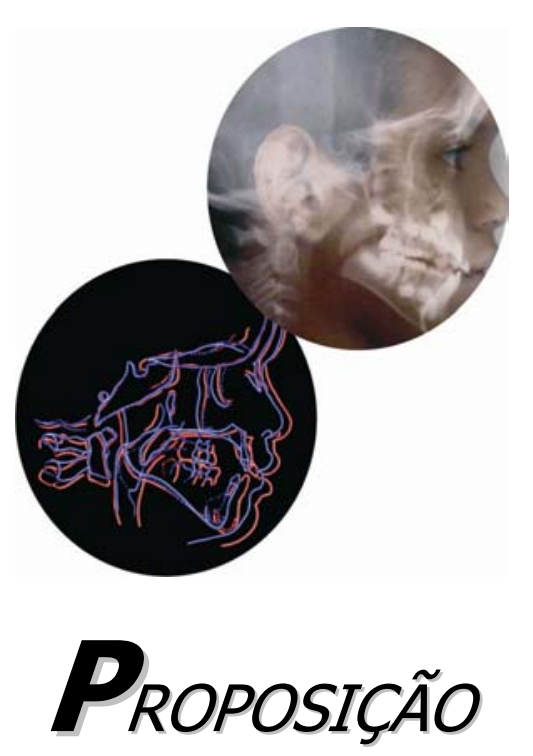




\section{Proposição}

O objetivo deste estudo foi avaliar crianças respiradoras bucais, antes e, em média, 28 meses após serem submetidas à adenoidectomia e adenotonsilectomia, comparando-as com crianças respiradoras nasais, nos seguintes aspectos:

1- padrão morfológico da face, por meio de medidas cefalométricas angulares e lineares

2- características oclusais, por meio de modelos de estudo ortodônticos. 
Material e Métodos 


\section{Material e Método}

\section{1) Seleção das crianças}

O presente projeto de pesquisa foi aprovado pelo Comitê de Ética em Pesquisa Envolvendo Seres Humanos da Faculdade de Odontologia de Ribeirão Preto, da USP, sob o processo $n^{\circ}$ 2000.1.483.58.5 (Anexo I). Foi utilizada amostra constituída de 73 crianças com idade variando entre 3 e 6 anos, de ambos os gêneros, pertencentes às raças branca e negra, no período de dentição decídua completa ou mista precoce. Foram excluídas da pesquisa, as crianças cujos dentes e arcadas dentárias apresentassem qualquer fator que pudesse comprometer a avaliação das características oclusais (ausência ou destruição das coroas dos segundos molares decíduos, caninos decíduos, incisivos superiores e inferiores) ou história prévia de cirurgias do complexo nasorrespiratório e/ou tratamento ortodôntico.

As crianças foram selecionadas mediante a apresentação para tratamento de saúde no Hospital das Clínicas, Ambulatório de Otorrinolaringologia da FMRP- USP, e para tratamento odontológico na Clínica de Ortodontia Preventiva da FORP- USP. Todas foram submetidas às avaliações otorrinolaringológicas e ortodônticas. Essas crianças efetuaram os exames após autorização dos pais ou responsáveis (Anexo II).

\section{2) Exame Otorrinolaringológico}

O diagnóstico otorrinolaringológico da respiração foi realizado no Serviço de Rinossinusiologia Pediátrica da Disciplina de Otorrinolaringologia do Hospital das Clínicas da Faculdade de Medicina de Ribeirão Preto - USP. Foram realizados os seguintes exames:

Questionário aplicado aos pais (Anexo III), avaliação clínica com exame físico, por meio de oroscopia, rinoscopia anterior e otoscopia.

$\mathrm{Na}$ oroscopia, foram utilizados os critérios de Brodsky e Kock (1992) para classificação da hipertrofia de tonsila palatina, sendo:

- Grau 0: tonsila limitada à fossa tonsilar

- Grau 1: tonsilas ocupando até $25 \%$ do espaço entre os pilares anteriores, na orofaringe 
- Grau 2: tonsilas entre 25 e 50\% do espaço entre pilares anteriores

- Grau 3: tonsilas entre 50 e $75 \%$ do espaço entre pilares anteriores

- Grau 4: entre 75 e 100\% do espaço entre pilares anteriores

Na rinoscopia foi avaliada a presença de desvio septal e hipertrofia de cornetos inferiores. Os pacientes que apresentavam desvio de septo foram eliminados do estudo.

Para avaliação adenoideana, foi utilizada a radiografia lateral, sendo realizada pelo método de Cohen e Konak (1985), uma vez que, segundo Wormald e Prescott (1992), trata-se de um método radiológico com maior valor predictivo, comparando-se à nasofibroscopia (com variação máxima entre os resultados de $10 \%$ de diferença). Segundo Monteiro et al. (2000), estatisticamente, os resultados dos dois exames são semelhantes, apesar de maior variabilidade no exame radiográfico. A avaliação das tonsilas faríngeas, em radiografias laterais, é feita comparando a espessura do palato mole e a porção ântero-superior da coluna aérea, imediatamente posterior ao palato (ponto de maior convexidade da adenóide), traçando-se uma linha perpendicular ao palato mole, a $1 \mathrm{~cm}$ abaixo do limite superior do palato mole, em crianças maiores de 3 anos e a $0.5 \mathrm{~cm}$, para crianças menores de 3 anos (Figura 1). Se a coluna aérea for mais espessa que o palato mole, é classificada como normal; quando é mais estreita, porém, mais espessa que a metade da espessura do palato, é classificada como média; e, quando mais estreita que a metade da espessura do palato, é considerada hipertrófica.

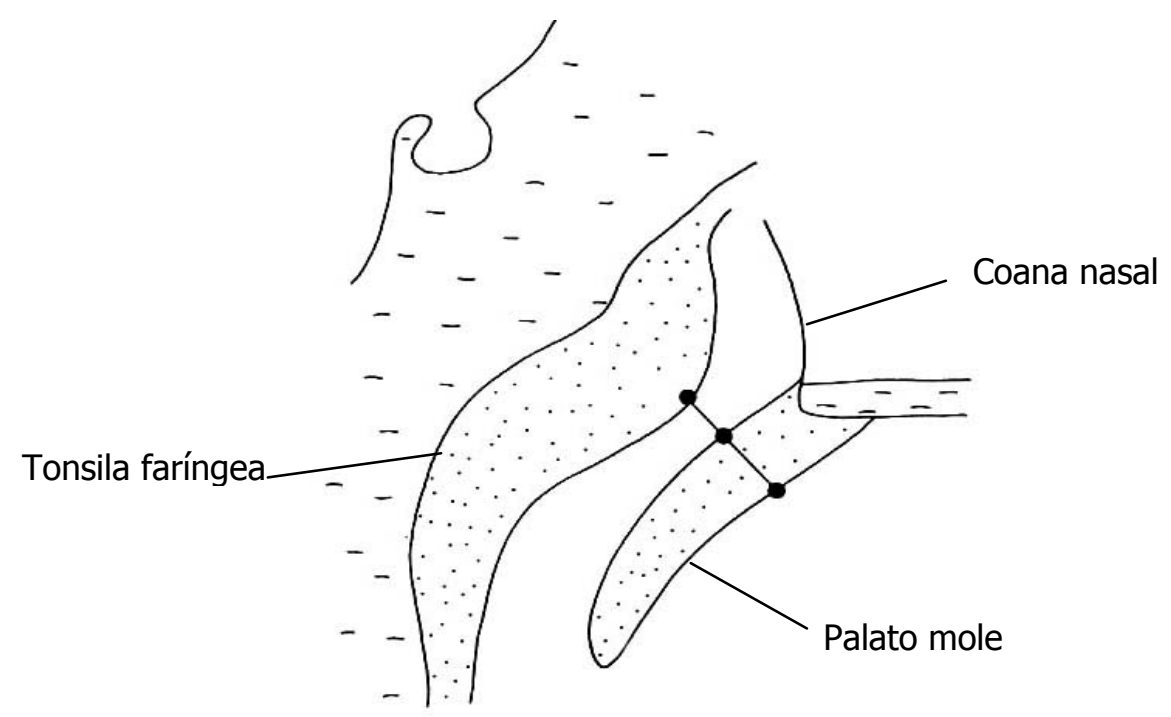

Figura 1 - Esquema das características anatômicas avaliadas na radiografia da coluna aérea segundo método de Cohen e Konak (1985). 
Para o diagnóstico da respiração, por meio da avaliação otorrinolaringológica, a amostra foi dividida em dois grupos distintos. O grupo considerado como experimental (RB) foi constituído por 44 crianças respiradoras bucais, entre 3 e 6 anos de idade, com alto grau de obstrução das vias aéreas devido à hipertrofia de tonsilas palatinas e/ou faríngea, com indicação cirúrgica de remoção das tonsilas. O grupo controle (RN) foi composto por 29 crianças respiradoras nasais, entre 3 e 6 anos de idade, que não apresentavam nenhum tipo de obstrução das vias aéreas.

As crianças de ambos os grupos, controle e experimental, foram encaminhadas para avaliação ortodôntica. Em seguida, as do grupo RB foram submetidas à adenoidectomia, devido à hipertrofia das tonsilas faríngeas ou adenotonsilectomia, devido à hipertrofia de tonsilas palatinas e faríngeas, no Hospital das Clínicas de Ribeirão Preto da Faculdade de Medicina de Ribeirão Preto - USP.

\section{3) Avaliação ortodôntica}

A avaliação ortodôntica consistiu de exame clínico intra e extra-oral, modelos de estudo das arcadas dentárias, radiografias cefalométricas em norma lateral, que foram obtidas antes, e em média 28 meses após o procedimento cirúrgico. Realizou-se também entrevista com os pais ou responsáveis pelas crianças, para preenchimento da ficha de anamnese. Todos os dados obtidos foram registrados em protocolo próprio, inclusive os dados do exame clínico intra e extra-oral (Anexo IV).

Para obtenção dos modelos de estudo, foram moldadas as arcadas dentárias superior e inferior de todos os pacientes, utilizando-se moldeiras ortodônticas (TP Orthodontics, Inc. $\mathrm{n}^{\circ}$ 110-002) e material de moldagem com hidrocolóide irreversível - (Jeltrate, tipo IV - Dentsply Indústria e Comércio Ltda). As moldagens foram vazadas com gesso tipo III (Empresa Industrial Gesso Mossoró S/A), na proporção água/pó recomendada pelo fabricante e posteriormente, foi realizado o acabamento manual. O registro da mordida em oclusão habitual foi tomado em uma lâmina de cera rosa $n^{\circ} 7$, Wilson (Polidental Indústria e Comércio Ltda).

Os modelos de estudo foram avaliados quanto às seguintes características oclusais:

1. relação ântero-posterior de caninos decíduos (Honda, 1997 - Figura 2):

1.1 classe I: canino superior ocluindo na distal do inferior 
1.2 classe II: canino superior ocluindo na mesial do inferior

1.3 classe III: canino superior ocluindo muito à distal do inferior

1.4 topo: canino superior ocluindo de topo com o inferior

2. plano terminal dos segundos molares decíduos (Baume, 1959; Honda, 1997- Figura 2, 3):

2.1 reto: posição ântero-posterior das superfícies distais dos segundos molares decíduos antagonistas localizadas no mesmo plano vertical

2.2 degrau mesial: superfície distal do segundo molar decíduo inferior, se localiza mesial a do segundo molar decíduo superior

2.3 degrau distal: superfície distal do segundo molar decíduo inferior, se localiza distal a do segundo molar decíduo superior

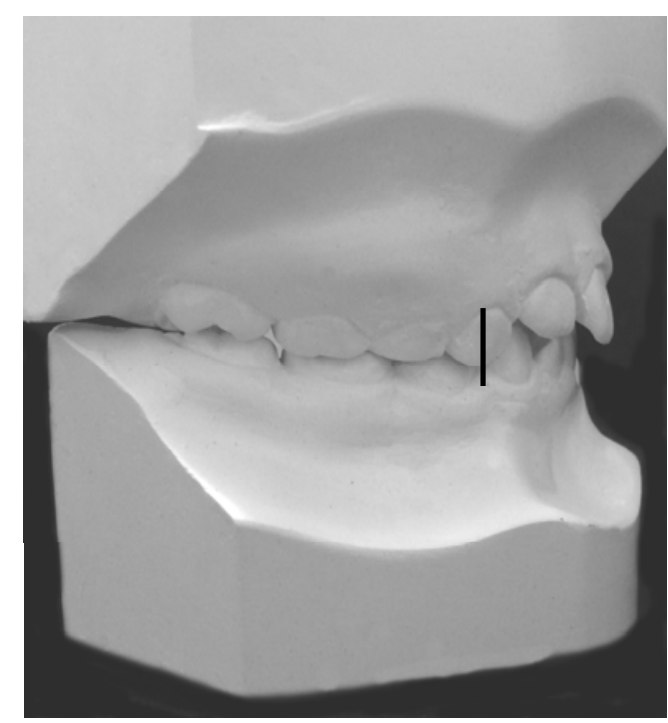

Figura 2 - Modelos de estudo em oclusão para avaliação da relação ântero-posterior de caninos decíduos
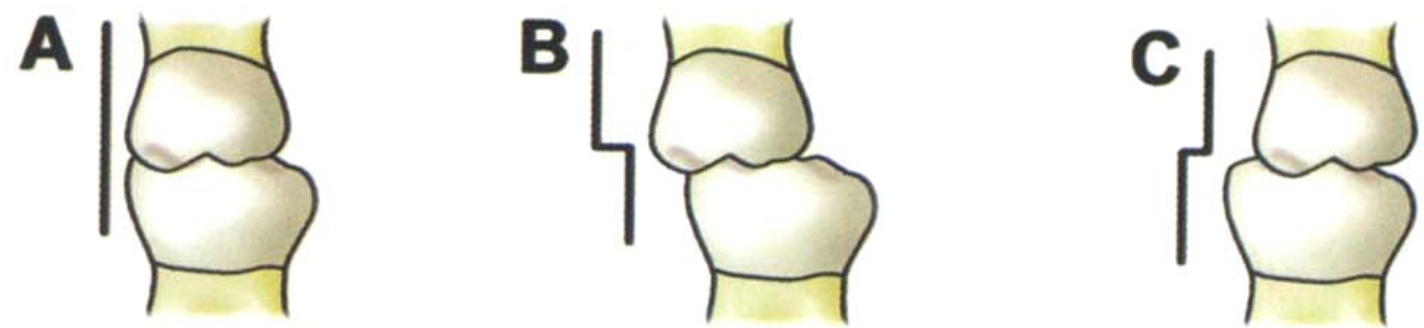

Figura 3 - Plano terminal dos segundos molares decíduos: A) reto; B) mesial; C) distal ( McDonald e Avery, 1995). 
3. presença ou ausência de mordida cruzada posterior (Figura 4)

4. presença ou ausência de mordida aberta anterior (Figura 5)

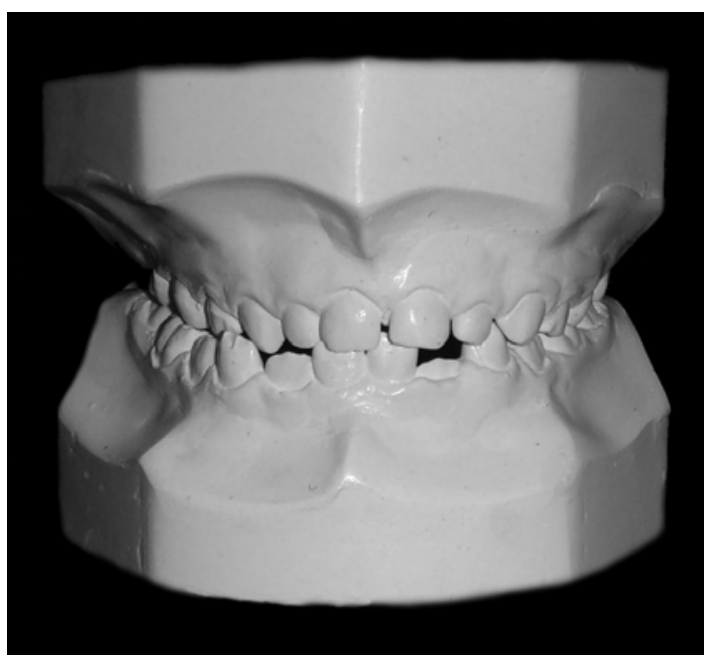

Figura 4 - Mordida cruzada posterior.

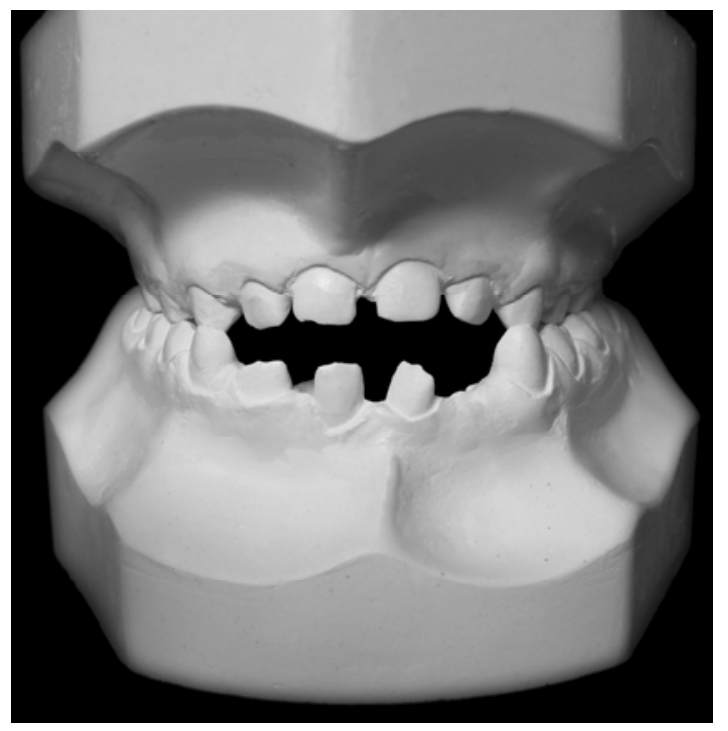

Figura 5 - Mordida aberta anterior.

5. overbite (sobremordida): distância vertical entre as bordas incisais dos incisivos superiores e inferiores (Araújo, 1983). Classificado em:

5.1 normal: trespasse do incisivo superior até o terço incisal da coroa do incisivo inferior

5.2 profundo: trespasse do incisivo superior à partir do terço médio, até o terço cervical da coroa do incisivo inferior

5.3 negativo: ausência de trepasse do incisivo superior em relação ao inferior. 
6. overjet (sobressaliência): distância horizontal em milímetros $(\mathrm{mm})$ entre a borda incisal do incisivo central superior mais protruído e a face vestibular do incisivo central inferior (Figura 6).

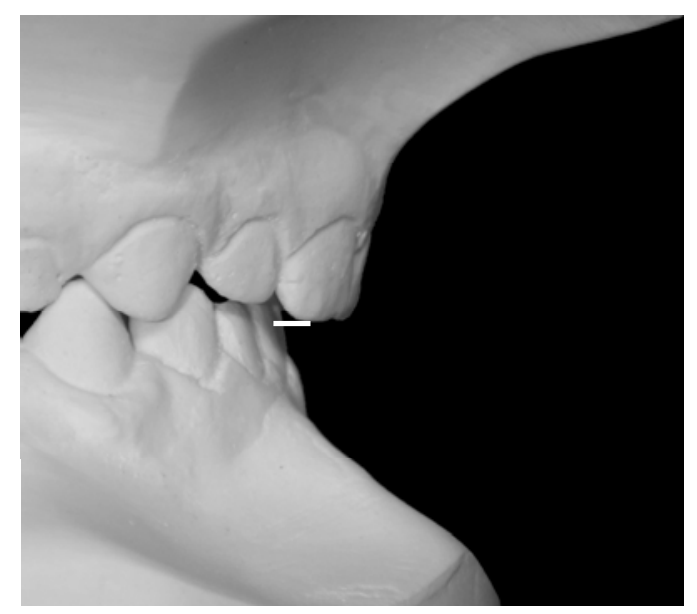

Figura 6 - Vista lateral dos modelos de estudo ocluídos para medição de overjet.

7. distância intercaninos: distância em milímetros do ponto mais cervical do centro da face vestibular dos caninos decíduos superiores direito e esquerdo (Figura 7).

8. distância intermolares: distância em milímetros da porção mais cervical do centro da cúspide mésio-vestibular dos segundos molares decíduos superiores direito e esquerdo (Figura 7).

A medição do overjet foi realizada por meio de régua milimetrada de aço (Dentaurum 044-731-00) e para medição das distâncias intercaninos e intermolares, foi usado um compasso de pontas secas ortodôntico (Dentaurum 030-395-0).

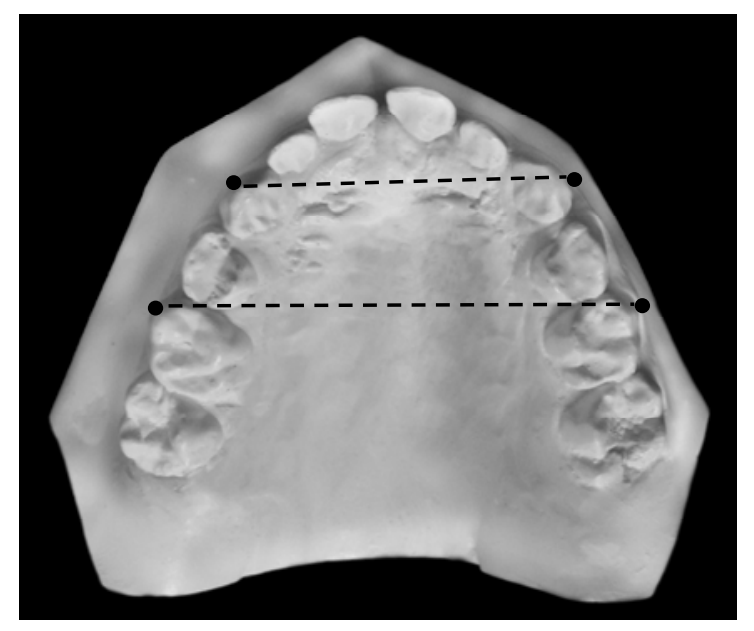

Figura 7 - Vista oclusal da arcada superior com distâncias intercaninos e intermolares. 
As tomadas das radiografias cefalométricas em norma lateral foram realizadas por um único técnico responsável pelo Laboratório de Análise e Controle da Imagem Radiográfica Odontológica (LACIRO), da Disciplina de Radiologia, da FORPUSP. Durante a tomada radiográfica, utilizou-se avental de chumbo para proteção dos pacientes. Foi empregada a técnica convencional preconizada por Broadbent (1981), sendo os pacientes posicionados com o tórax e a cabeça em posição vertical, para que o meato acústico externo alcançasse o nível dos posicionadores das olivas auriculares do cefalostato, permitindo que o plano sagital mediano formasse um ângulo reto com a fonte de raios $X$ e o plano horizontal de Frankfurt, paralelo ao solo. A cabeça do paciente foi mantida firme ao instrumento pelo indicador do násio. Os pacientes mantiveram postura relaxada, os dentes em oclusão cêntrica, e os lábios em posição natural (Haiter-Neto et al., 2007).

O aparelho de raios $X$ extrabucal utilizado foi da marca Orthophos CD (SIEMENS). Utilizaram-se filmes Kodak T-MAT (Eastman Kodak Company) montados em chassis, providos de ecran intensificador tipo verde, no tamanho $18 \times 24 \mathrm{~cm}$, com o tempo de exposição de 1 segundo, 16 miliamperes e 60 kv. As radiografias foram reveladas pelo método tempo/temperatura, fixadas durante 15 minutos, lavadas em água corrente durante 20 minutos, e secas em ambiente apropriado.

Em cada radiografia cefalométrica foi superposta uma folha de papel de acetato transparente "Ultraphan", tamanho $17,5 \mathrm{~cm} \times 17,5 \mathrm{~cm}$, e fixada em três pontos por meio de fita adesiva. Os traçados dos contornos das estruturas anatômicas dentofaciais e de tecidos moles foram realizados pelo método manual, em uma sala escura, sobre um negatoscópio. Utilizou-se lapiseira com grafite de 0,5mm de espessura, régua milimetrada, transferidor, borracha e "tooth tracing template" (Unitek Corporation), para a confeç̧ão dos traçados cefalométricos. Os valores angulares foram obtidos utilizando-se sempre o mesmo transferidor e os valores lineares, a mesma régua milimetrada. As frações de medidas foram corrigidas para números inteiros ou para 0,5 grau ou $0,5 \mathrm{~mm}$.

Nos cefalogramas foram demarcados os seguintes pontos cefalométricos:

ponto Sela (S) - ponto situado no centro geométrico da sela turca;

ponto Násio $(\mathrm{N})$ - ponto mais anterior da sutura frontonasal;

ponto A (subespinhal) - ponto mais profundo do contorno da pré- maxila, entre a espinha nasal anterior e o próstio; 
ponto B (supramental) - ponto mais profundo do contorno do processo alveolar da mandíbula entre os pontos infradental e pogônio;

ponto Gônio (Go) - ponto localizado na interseção da bissetriz do ângulo formado por tangentes às bordas posterior e inferior da mandíbula com o ângulo goníaco;

ponto Mentoniano (Me) - ponto localizado na interseção entre a cortical externa do mento e a cortical inferior do corpo mandibular. Ponto mais inferior do contorno da sínfise mandibular;

ponto Básio $(\mathrm{Ba})$ - ponto mais inferior sobre a margem anterior do forame magno;

ponto Espinha Nasal Anterior (ENA)- ponto situado na extremidade anterior da maxila;

ponto Espinha Nasal Posterior (ENP) - ponto situado na extremidade posterior da maxila;

ponto Pterigóide (Pt) - ponto localizado na parte mais posterior e superior do contorno superior da fissura ptérigo maxilar;

ponto Gnátio (Gn) - ponto mais anterior e inferior da sínfise mandibular, determinado pela bissetriz do ângulo formado entre o plano mandibular e uma perpendicular a este, que tangencie a região mais anterior da sínfise;

ponto Articular (Ar) - ponto situado na interseção do contorno posterior do processo condilar da mandíbula com a base do osso occipital.

Após a localização dos 12 pontos anatômicos esqueletais de referências, obtiveram-se as seguintes medidas cefalométricas angulares e lineares (Figuras 8 e 9):

1. Ângulo SNA: descreve a posição maxilar em relação à base do crânio (Águila, 1997).

2. Ângulo SNB: reflete a posição ântero-posterior mandibular em relação à base do crânio (Águila, 1997).

3. Ângulo ANB: formado pelo cruzamento das linhas N-A e N-B. Mede a relação ântero-posterior da maxila com a mandíbula (Águila, 1997).

4. Ângulo SN.GoGn: determinado pela interseção da linha S-N com o plano mandibular (Go-Gn). Expressa o grau de inclinação do plano mandibular em relação à base anterior do crânio (Araújo, 1983; Vilella, 1998). 
5. Ângulo SN.PP: formado pela interseção da linha S-N com o plano palatal (ENAENP). Estabelece o grau de inclinação da maxila em relação à base anterior do crânio (Águila, 1997).

6. Ângulo PP.PM: estabelecido pela intersecção do plano palatal (ENA-ENP) com o plano mandibular (Go-Me). Relaciona a maxila à mandíbula no plano vertical (Nanda, 1955; Chang et al., 1993).

7. Ângulo ArGo.GoMe (ângulo goníaco): determinado pela junção da linha ArGo com GoMe. Estabelece o grau de inclinação do ramo com o corpo da mandíbula (McDonald \& Avery, 1995).

8. Ângulo SNGn: corresponde à direção do crescimento da face (Águila, 1997; Araújo, 1983).

9. Ângulo BaN.PtGn: expressa a variação da altura facial e a profundidade facial (Águila, 1997; Araújo,1983; Ricketts, 1961).

10. N-Me: medida linear correspondente à altura total anterior da face (Wylie \& Johnson, 1952; Scheideman et al., 1980).

11. N-ENA: representa a altura anterior superior da face (Wylie \& Johnson, 1952; Scheideman et al., 1980).

12. ENA-Me: estabelece a altura anterior inferior da face (Wylie \& Johnson,1952; Scheideman et al., 1980).

13. S-Go: medida linear que representa a altura posterior da face (Águila, 1997).

14. S-Ar: corresponde à altura posterior superior da face (Águila, 1997).

15. Ar-Go: corresponde à altura posterior inferior da face (Chang et al., 1993). 


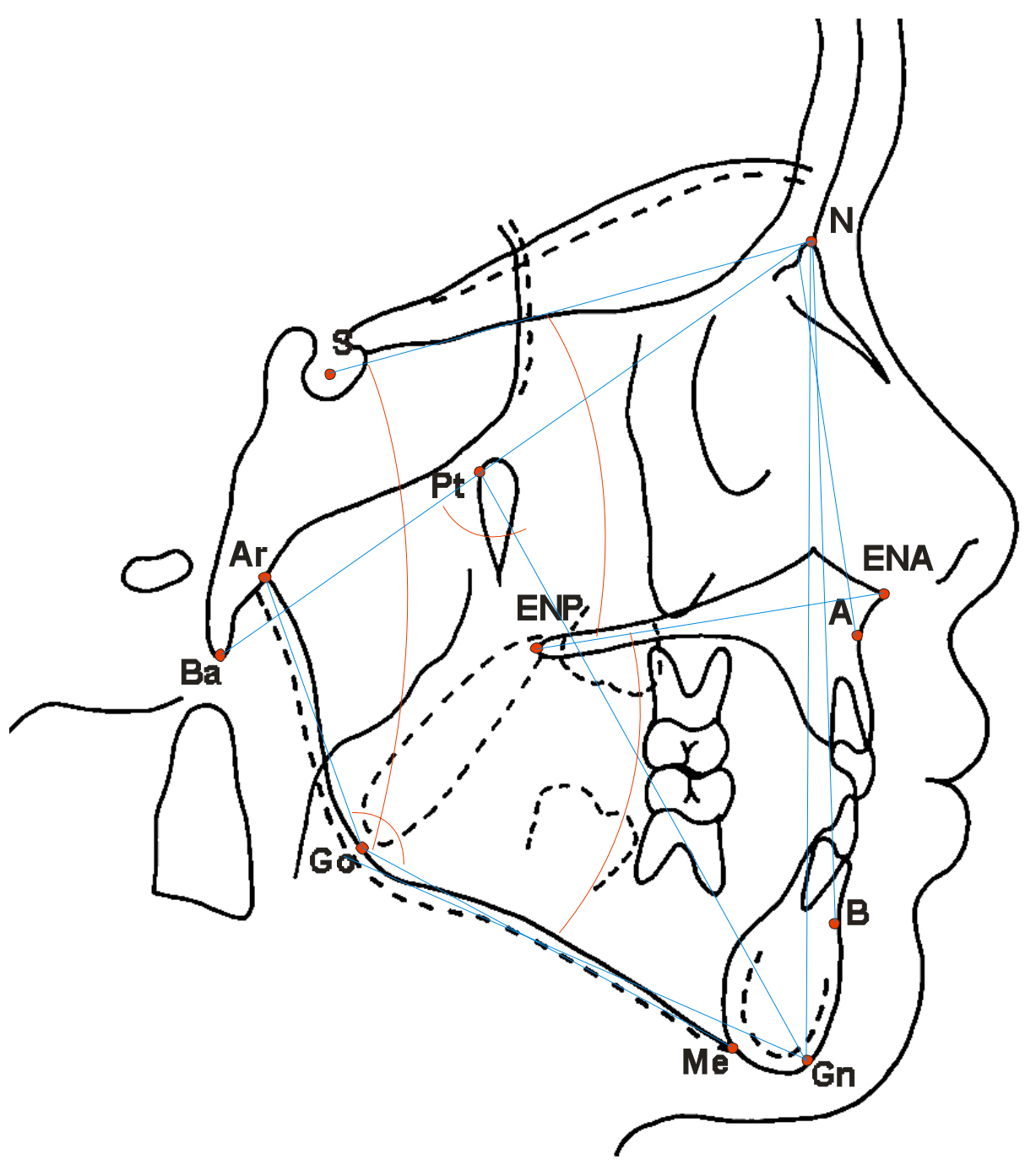

Figura 8 - Traçado das estruturas anatômicas dentofaciais, tecidos moles e pontos cefalométricos utilizados no estudo. Cefalograma ilustrando as medidas cefalométricas angulares. 


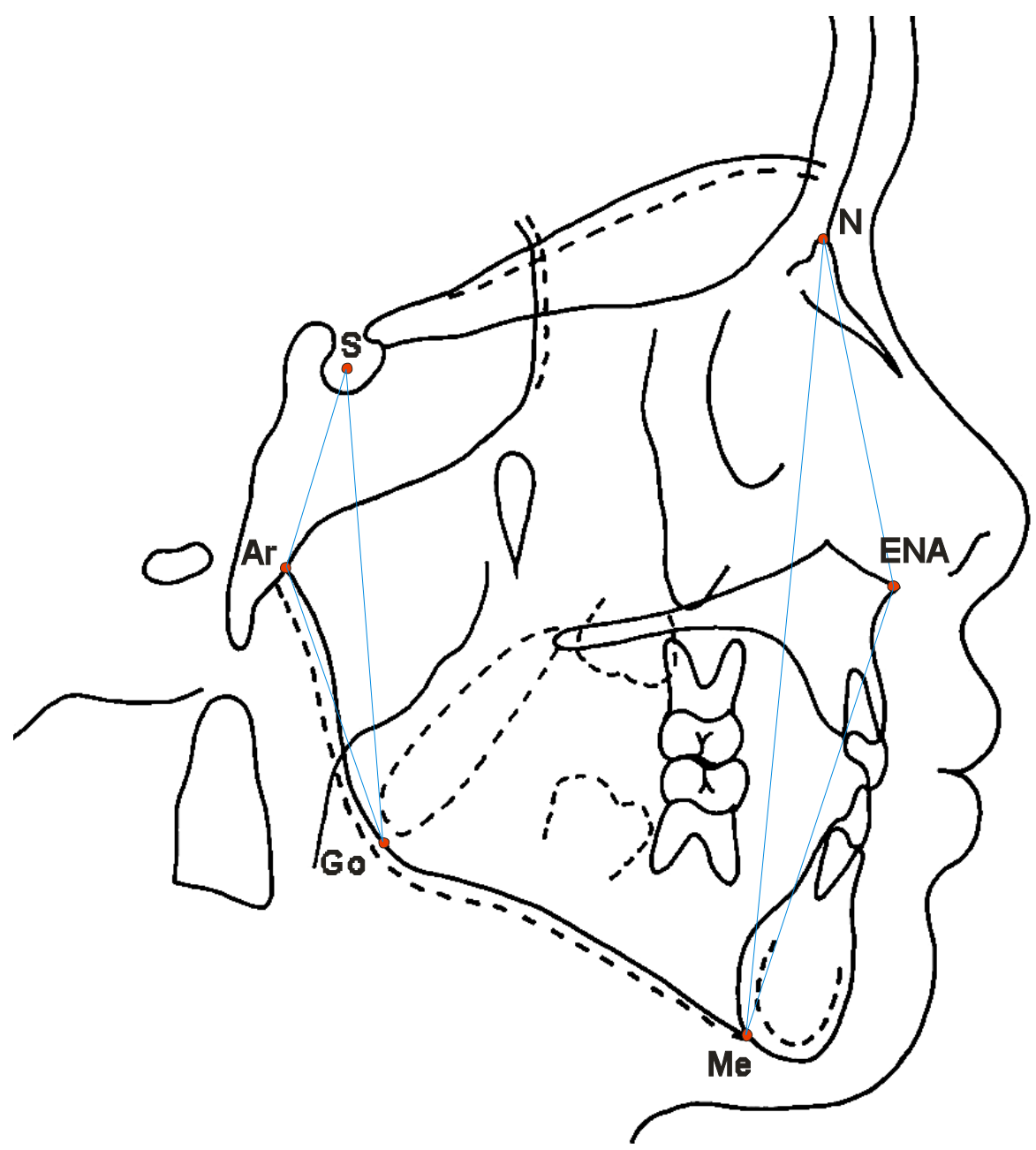

Figura 9 - Cefalograma ilustrando as medidas cefalométricas lineares. 


\section{4) Avaliação pós-cirúrgica}

Os exames otorrinolaringológicos foram realizados antes da intervenção cirúrgica e depois de 1, 6, 12 e 24 meses da cirurgia. A avaliação pós-operatória otorrinolaringológica enfatizou a presença ou não de sintomas ou sinais de obstrução respiratória após a intervenção cirúrgica. Crianças com moderada rinite alérgica foram medicadas e mantidas em estudo no grupo RB, enquanto as que apresentaram tonsilas faríngeas recorrentes foram excluídas da avaliação.

A amostra final do presente estudo foi constituída de 55 crianças com idade entre 5 e 8 anos, sendo 33 respiradores bucais e 22 respiradores nasais. Dezoito pacientes da amostra inicial foram eliminados por: não se submeterem às avaliações propostas no estudo, não apresentarem elementos adequados para inclusão em um dos grupos quanto à integridade dos dentes e arcadas; terem se submetido a tratamento ortodôntico; apresentarem tonsila faríngea hipertrófica recorrente após a cirurgia.

Os dados obtidos nas avaliações ortodônticas (anamnese, análise dos modelos de estudo e avaliações cefalométricas) dos grupos de respiradores bucais e nasais foram organizados em tabelas, considerando-se dois momentos de avaliação: tempo 1 ( $(\mathrm{T} 1)$ que são os exames iniciais e, tempo 2 (T2), exames realizados em média 28 meses após a intervenção cirúrgica. A média de idade do grupo RB foi de 4 anos e 3 meses em T1 e de 7 anos e 2 meses em T2. A média de idade do grupo RN foi de 5 anos e 1 mês em T1 e de 7 anos e 4 meses em T2.

\section{5) Tratamento estatístico}

Os dados obtidos por meio de anamnese, análise de modelos e análise cefalométrica foram tratados utilizando-se o programa estatístico Graph Pad Prism 4 (Graph Pad Software In., San Diego, Califórnia, EUA). Foram efetuadas as comparações citadas abaixo, referentes às medidas cefalométricas e às características oclusais. 


\section{Medidas cefalométricas}

Comparação das médias das medidas cefalométricas entre grupos RB e RN no tempo T1, por meio do teste t de Student;

Comparação das médias das medidas cefalométricas entre grupos RB e RN no tempo T2 por meio do teste t de Student;

Comparação das médias das medidas cefalométricas entre tempos T1 e T2 nos grupos RB e RN, por meio do teste t pareado;

Comparação da variação média das medidas cefalométricas (T2-T1) entre os grupos RB e RN, por meio do teste t de Student.

\section{Características oclusais}

Comparação das médias das medidas oclusais entre os grupos RB e RN no tempo T1 por meio do teste t de Student;

Comparação das médias das medidas oclusais entre os grupos RB e RN no tempo T2 por meio do teste t de Student;

Comparação das médias das medidas oclusais entre os tempos T1 e T2 nos grupos RB e RN, por meio do teste t pareado;

Comparação da variação média das medidas oclusais (T2-T1) entre os grupos RB e RN, por meio do teste t de Student;

Comparação das características oclusais entre os grupos RB e RN no tempo T1, por meio do teste quiquadrado e Mann Whitney.

Comparação das características oclusais entre os grupos RB e RN no tempo T2, por meio do teste quiquadrado e Mann Whitney;

Comparação das características oclusais entre os tempos T1 e T2 dentro de cada grupo, por meio do teste Mac-Nemar e Wilcoxon e quiquadrado;

Comparação da variação das características oclusais entre os grupos RB e RN, por meio do teste quiquadrado e Mann Whitney. 


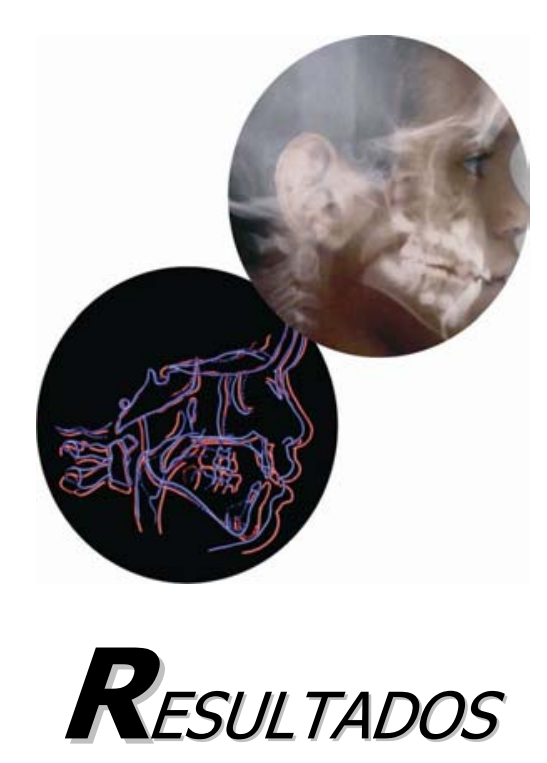




\section{RESULTADOS}

\section{1) Medidas cefalométricas}

A Tabela 1 mostra as comparações das médias das medidas cefalométricas entre os Grupos RB e RN no momento T1. As medidas SN.GoGn, PP.PM e ArGo.GoMe apresentaram-se estatisticamente maiores, enquanto que os valores de BaN.PtGn, S-Go e Ar-Go mostraram-se estatisticamente menores no grupo RB em relação ao RN. Essas medidas estão relacionadas com a posição espacial da mandíbula e altura facial posterior, sendo que as diferenças encontradas podem sugerir alteração na direção de crescimento mandibular e rotação da mandíbula no sentido horário no grupo RB. Nas demais medidas não foram encontradas diferenças estatisticamente significantes.

Tabela 1 - Comparação das medidas cefalométricas entre grupos RB e RN no tempo T1, por meio do teste $t$ de Student

\begin{tabular}{l|rr|rrc}
\hline \multicolumn{1}{c|}{ Medidas } & \multicolumn{4}{|c|}{ Grupo RB (T1) } & \multicolumn{3}{c}{ Grupo RN (T1) } \\
\hline & Média & DP & Média & DP & P \\
\hline SNA $\left(^{\circ}\right)$ & 81,7 & 3,9 & 82,81 & 4,6 & $0,324 \mathrm{~ns}$ \\
SNB $\left(^{\circ}\right)$ & 75,8 & 2,8 & 77,7 & 5,1 & $0,081 \mathrm{~ns}$ \\
ANB $\left(^{\circ}\right)$ & 5,8 & 2,3 & 5,4 & 1,7 & $0,488 \mathrm{~ns}$ \\
SN.GoGn $\left(^{\circ}\right)$ & 41,2 & 4,8 & 36,6 & 4,8 & $<0,001 * *$ \\
SN.PP $\left(^{\circ}\right)$ & 6,1 & 3,1 & 6,0 & 3,8 & $0,915 \mathrm{~ns}$ \\
PP.PM $\left(^{\circ}\right)$ & 37,2 & 4,2 & 32,7 & 6,0 & $0,002 * *$ \\
ArGo.GoMe $\left(^{\circ}\right)$ & 136,9 & 3,6 & 131,3 & 3,2 & $<0,0001^{* * *}$ \\
SNGn $\left(^{\circ}\right)$ & 70,8 & 3,5 & 69,2 & 4,8 & $0,159 \mathrm{~ns}$ \\
BaN.PtGn( $\left.{ }^{\circ}\right)$ & 84,2 & 3,9 & 88,2 & 3,2 & $<0,0001^{* * *}$ \\
N-Me $(\mathrm{mm})$ & 100,1 & 5,2 & 99,0 & 4,8 & $0,432 \mathrm{~ns}$ \\
N-ENA (mm) & 43,1 & 2,9 & 43,1 & 2,8 & $1,000 \mathrm{~ns}$ \\
ENA-Me(mm) & 60,1 & 3,8 & 59,2 & 3,5 & $0,379 \mathrm{~ns}$ \\
S-Go (mm) & 58,2 & 3,3 & 60,4 & 4,4 & $0,039 *$ \\
S-Ar (mm) & 27,4 & 2,8 & 28,2 & 3,4 & $0,33 \mathrm{~ns}$ \\
Ar-Go (mm) & 33,3 & 2,7 & 35,8 & 4,4 & $0,012 *$ \\
\hline
\end{tabular}

$(\mathrm{mm})$ milímetro; $\left({ }^{\circ}\right)$ grau; $n s=$ não significante; $\mathrm{DP}=$ desvio padrão; $* \mathrm{p}<0,05$ ； $* * \mathrm{p}<0,01 ; \quad * * * \mathrm{p}<0,001$ 
Comparando-se as medidas cefalométricas entre os Grupos RB e RN no momento T2, verificou-se que a média do eixo facial (BaN.PtGn) apresentou-se estatisticamente maior no grupo RN (Tabela 2). As demais medidas se encontravam semelhantes estatisticamente. Isso sugere que em T2 as amostras se apresentavam mais homogêneas, porém, ainda com diferença no padrão morfológico da face. No grupo RN ressaltou-se tendência ao padrão morfológico mesofacial e no grupo RB dolicofacial.

Tabela 2 - Comparação das medidas cefalométricas entre grupos RB e RN no tempo T2 por meio do teste t de Student

\begin{tabular}{l|cc|ccc}
\hline \multicolumn{1}{c|}{ Medidas } & \multicolumn{3}{|c|}{ Grupo RB (T2) } & \multicolumn{3}{c}{ Grupo RN (T2) } \\
\hline & Média & DP & Média & DP & P \\
\hline SNA $\left(^{\circ}\right)$ & 82,5 & 3,8 & 82,1 & 4,5 & $0,742 \mathrm{~ns}$ \\
SNB $\left(^{\circ}\right)$ & 76,6 & 3,1 & 77,6 & 4,2 & $0,314 \mathrm{~ns}$ \\
ANB $\left(^{\circ}\right)$ & 5,8 & 2,0 & 5,0 & 1,7 & $0,11 \mathrm{~ns}$ \\
SN.GoGn $\left(^{\circ}\right)$ & 38,8 & 5,1 & 36,6 & 5,3 & $0,129 \mathrm{~ns}$ \\
SN.PP $\left(^{\circ}\right)$ & 6,3 & 3,5 & 6,4 & 3,3 & $0,916 \mathrm{~ns}$ \\
PP.PM $\left({ }^{\circ}\right)$ & 34,5 & 4,4 & 32,1 & 6,1 & $0,096 \mathrm{~ns}$ \\
ArGo.GoMe $\left(^{\circ}\right)$ & 133,4 & 3,6 & 134,2 & 5,4 & $0,512 \mathrm{~ns}$ \\
SNGn $\left(^{\circ}\right)$ & 69,6 & 3,5 & 69,1 & 5,2 & $0,671 \mathrm{~ns}$ \\
BaN.PtGn( $\left(^{\circ}\right)$ & 86,0 & 3,9 & 89,0 & 3,0 & $0,004 * * *$ \\
N-Me $(\mathrm{mm})$ & 105,6 & 5,1 & 105,5 & 5,5 & $0,945 \mathrm{~ns}$ \\
N-ENA (mm) & 46,4 & 3,1 & 46,7 & 2,7 & $0,713 \mathrm{~ns}$ \\
ENA-Me(mm) & 62,2 & 3,3 & 61,4 & 4,1 & $0,428 \mathrm{~ns}$ \\
S-Go (mm) & 63,0 & 3,5 & 64,1 & 5,8 & $0,384 \mathrm{~ns}$ \\
S-Ar (mm) & 29,9 & 2,3 & 30,5 & 2,9 & $0,397 \mathrm{~ns}$ \\
Ar-Go (mm) & 35,9 & 3,0 & 37,5 & 4,6 & $0,124 \mathrm{~ns}$ \\
\hline
\end{tabular}

(mm) milímetro; $\left({ }^{\circ}\right)$ grau; ns=não significante; DP = desvio padrão; $* * * p<0,001$

A Tabela 3 mostra os resultados das comparações das medidas cefalométricas entre os tempos T1 e T2 nos grupos RB e RN. No grupo RB, observouse que as medidas SNA, SN.GoGn, PP.PM, ArGo.GoMe, SNGn, BaN.PtGn, N-Me, NENA, ENA-Me, S-Go, S-Ar, Ar-Go apresentaram alterações estatisticamente significantes. No grupo RN, houve diferença estatisticamente significante nas medidas cefalométricas ArGo.GoMe, N-Me, N-ENA, ENA-Me, S-Go, S-Ar, Ar-Go. É interessante salientar que as medidas SNA, SN.GoGn, PP.PM, SNGn e BaN.PtGn tiveram mudanças significantes somente no Grupo RB, onde os pacientes sofreram intervenção cirúrgica. A diminuição na média das medidas SN.GoGn, PP.PM, SNGn, ArGo.GoMe e aumento 
na média da medida BaN.PtGn, evidencia alteração na direção do crescimento da face e inclinação do plano mandibular no sentido anti-horário no grupo RB, após a desobstrução cirúrgica das vias aéreas. No grupo RN as medidas relacionadas com a posição espacial da maxila e da mandíbula se mantiveram estáveis. O ângulo goníaco aumentou levemente no período de tempo avaliado. Todas as medidas verticais lineares (N-Me, N-ENA, ENA-Me, S-Go, S-Ar, Ar-Go) apresentaram aumento de T1 para T2 nos dois grupos, mostrando que ocorreu crescimento vertical anterior e posterior da face e que foi semelhante nas duas amostras.

Tabela 3 - Comparação das medidas cefalométricas entre os tempos T1 e T2 nos grupos RB e RN, por meio do teste $t$ pareado

\begin{tabular}{|c|c|c|c|c|c|c|c|c|c|c|}
\hline \multicolumn{6}{|c|}{ Grupo RB } & \multicolumn{5}{|c|}{ Grupo RN } \\
\hline \multirow[t]{2}{*}{ Medidas } & \multicolumn{2}{|c|}{ Inicial - T1 } & \multicolumn{3}{|c|}{ Final - T2 } & \multicolumn{2}{|c|}{ Inicial -T1 } & \multicolumn{2}{|c|}{ Final- T2 } & \multirow[b]{2}{*}{$\mathbf{P}$} \\
\hline & Média & DP & Média & DP & $\mathbf{P}$ & Média & DP & Média & DP & \\
\hline SNA $\left({ }^{\circ}\right)$ & 81,65 & 3,87 & 82,5 & 3,8 & $0,02 *$ & 82,81 & 4,6 & 82,17 & 4,5 & $0,53 \mathrm{~ns}$ \\
\hline $\operatorname{SNB}\left({ }^{\circ}\right)$ & 75,8 & 2,8 & 76,6 & 3,1 & $0,54 \mathrm{~ns}$ & 77,7 & 5,1 & 77,6 & 4,2 & $0,82 \mathrm{~ns}$ \\
\hline ANB $\left(^{\circ}\right)$ & 5,8 & 2,3 & 6,0 & 2,2 & $0,56 \mathrm{~ns}$ & 5,4 & 1,7 & 4,8 & 1,9 & $0,11 \mathrm{~ns}$ \\
\hline SN.GoGn $\left({ }^{\circ}\right)$ & 41,2 & 4,8 & 38,8 & 5,1 & $<0,0001 * * *$ & 36,6 & 4,8 & 36,6 & 5,3 & $0,94 \mathrm{~ns}$ \\
\hline SN.PP $\left(^{\circ}\right)$ & 6,1 & 3,1 & 6,3 & 3,5 & $0,47 \mathrm{~ns}$ & 6,0 & 3,8 & 6,4 & 3,3 & $0,47 \mathrm{~ns}$ \\
\hline PP.PM $\left(^{\circ}\right)$ & 37,2 & 4,2 & 34,5 & 4,4 & $<0,0001^{* * *}$ & 32,7 & 6,0 & 32,1 & 6,1 & $0,50 \mathrm{~ns}$ \\
\hline $\operatorname{ArGo} . \mathrm{GoMe}\left({ }^{\circ}\right)$ & 136,9 & 3,6 & 133,4 & 3,6 & $<0,0001 * * *$ & 131,3 & 3,2 & 134,2 & 5,4 & $0,02 *$ \\
\hline SNGn $\left({ }^{\circ}\right)$ & 70,8 & 3,5 & 69,6 & 3,5 & $0,0031^{* *}$ & 69,2 & 4,8 & 69,1 & 5,2 & $0,70 \mathrm{~ns}$ \\
\hline BaN.PtGn $\left({ }^{\circ}\right)$ & 84,2 & 3,9 & 86,0 & 3,9 & $<0,0001 * * *$ & 88,2 & 3,2 & 89,0 & 3,0 & $0,09 \mathrm{~ns}$ \\
\hline $\mathrm{N}-\mathrm{Me}(\mathrm{mm})$ & 100,1 & 5,2 & 105,6 & 5,1 & $<0,0001 * * *$ & 99,0 & 4,8 & 105,5 & 5,5 & $<0,0001 * * *$ \\
\hline N-ENA (mm) & 43,1 & 2,9 & 46,4 & 3,1 & $<0,0001 * * *$ & 43,1 & 2,8 & 46,7 & 2,7 & $<0,0001^{* * *}$ \\
\hline ENA-Me(mm) & 60,1 & 3,8 & 62,2 & 3,3 & $<0,0001 * * *$ & 59,2 & 3,5 & 61,4 & 4,1 & $0,0004 * * *$ \\
\hline S-Go (mm) & 58,2 & 3,3 & 63,0 & 3,5 & $<0,0001 * * *$ & 60,4 & 4,4 & 64,1 & 5,8 & $<0,0001^{* * *}$ \\
\hline S-Ar (mm) & 27,4 & 2,8 & 29,9 & 2,3 & $<0,0001 * * *$ & 28,2 & 3,4 & 30,5 & 2,9 & $<0,0001 * * *$ \\
\hline Ar-Go (mm) & 33,3 & 2,7 & 35,9 & 3,0 & $<0,0001 * * *$ & 35,8 & 4,4 & 37,5 & 4,6 & $0,010 *$ \\
\hline
\end{tabular}

$(\mathrm{mm})$ milímetro; $\left({ }^{\circ}\right)$ grau; ns=não significante; DP = desvio padrão; $\quad * \mathrm{p}<0,05 ; \quad * * \mathrm{p}<0,01 ; \quad * * * \mathrm{p}<0,001$

Os resultados da comparação da variação da média das medidas cefalométricas entre os grupos RB e RN, apresentados na Tabela 4, mostraram que a média das medidas SNA, SN.GoGn, PP.PM, ArGo.GoMe apresentaram- se diferentes estatisticamente. A média das medidas SN.GoGn e PP.PM, sofreu diminuição significante no grupo RB, sugerindo rotação anterior da mandíbula. A variação quanto à medida ArGo.GoMe ocorreu de maneira estatisticamente diferente entre os grupos: no grupo RB a inclinação do corpo com o ramo mandibular diminuiu e no grupo RN, aumentou. 
Tabela 4 - Comparação da variação das medidas cefalométricas (T2-T1) entre os grupos RB e RN, por meio do teste $t$ de Student

\begin{tabular}{|c|c|c|c|c|c|}
\hline \multirow[t]{2}{*}{ Medidas } & \multicolumn{2}{|c|}{ T2-T1 (Grupo RB) } & \multicolumn{3}{|c|}{ T2-T1 (Grupo RN) } \\
\hline & Média & DP & Média & DP & $\mathbf{P}$ \\
\hline SNA $\left({ }^{\circ}\right)$ & 0,9 & 2,1 & $-0,6$ & 1,4 & $0,005^{* *}$ \\
\hline $\operatorname{SNB}\left({ }^{\circ}\right)$ & 0,8 & 2,2 & $-0,1$ & 1,9 & $0,123 \mathrm{~ns}$ \\
\hline ANB $\left(^{\circ}\right)$ & 0,2 & 1,8 & $-0,7$ & 1,9 & $0,081 \mathrm{~ns}$ \\
\hline SN.GoGn $\left(^{\circ}\right)$ & $-2,3$ & 2,6 & 0,0 & 3,0 & $0,004 * *$ \\
\hline SN.PP $\left(^{\circ}\right)$ & $-2,7$ & 2,0 & 0,4 & 2,4 & $0,871 \mathrm{~ns}$ \\
\hline PP.PM $\left(^{\circ}\right)$ & $-2,3$ & 2,6 & $-0,5$ & 3,6 & $0,005^{* *}$ \\
\hline $\operatorname{ArGo.GoMe}\left({ }^{\circ}\right)$ & $-3,5$ & 2,6 & 2,9 & 5,4 & $<0,0001 * * *$ \\
\hline SNGn $\left(^{\circ}\right)$ & $-1,2$ & 2,1 & $-0,1$ & 1,9 & 0,053 ns \\
\hline $\operatorname{BaN} . \operatorname{PtGn}\left({ }^{\circ}\right)$ & 1,9 & 2,3 & 0,8 & 2,1 & $0,078 \mathrm{~ns}$ \\
\hline $\mathrm{N}-\mathrm{Me}(\mathrm{mm})$ & 5,5 & 2,8 & 6,5 & 3,6 & $0,253 \mathrm{~ns}$ \\
\hline $\mathrm{N}-\mathrm{ENA}(\mathrm{mm})$ & 3,3 & 1,6 & 3,5 & 2,0 & $0,683 \mathrm{~ns}$ \\
\hline ENA-Me(mm) & 2,1 & 2,1 & 2,2 & 2,4 & $0,871 \mathrm{~ns}$ \\
\hline S-Go (mm) & 4,9 & 2,7 & 3,7 & 2,9 & $0,123 \mathrm{~ns}$ \\
\hline S-Ar (mm) & 2,5 & 2,1 & 2,3 & 1,7 & $0,711 \mathrm{~ns}$ \\
\hline Ar-Go (mm) & 2,6 & 3,2 & 1,7 & 2,8 & $0,288 \mathrm{~ns}$ \\
\hline
\end{tabular}

\section{2) Características oclusais}

No momento T1 a distância intercaninos (Dist III-III) e overjet, se mostraram semelhantes entre os grupos RB e RN (Tabela 5). A média dos valores das medidas transversais maxilares, referente à distância intermolares (Dist V-V), foi menor no grupo RB, caracterizando atresia da maxila em relação ao grupo RN. Quanto à comparação em T2 (Tabela 6), as medidas Dist III-III e Dist V-V se mostraram semelhantes. Porém, no T2 o overjet do grupo RB apresentou-se estatisticamente maior do que do grupo RN.

Tabela 5 - Comparação das medidas oclusais entre os grupos RB e RN no tempo T1 por meio do teste $t$ de Student

\begin{tabular}{l|cc|ccc}
\hline \multicolumn{1}{c|}{ Medidas } & \multicolumn{4}{|c|}{ Grupo RB (T1) } & \multicolumn{3}{c}{ Grupo RN (T1) } \\
\hline & Média & DP & Média & DP & P \\
\hline Dist III-III (mm) & 32,12 & 1,98 & 33,20 & 2,29 & $0,068 \mathrm{~ns}$ \\
Dist V-V (mm) & 46,77 & 2,62 & 47,75 & 2,79 & $0,019 *$ \\
Overjet (mm) & 3,10 & 2,0 & 2,25 & 1,07 & $0,07 \mathrm{~ns}$ \\
\hline
\end{tabular}

(mm) milímetro; ns=não significante; $\quad \mathrm{DP}=$ desvio padrão $\quad * \mathrm{p}<0,05$ 
Tabela 6 - Comparação das medidas oclusais entre os grupos RB e RN no tempo T2 por meio do teste t de Student

\begin{tabular}{l|cc|ccc}
\hline \multicolumn{1}{c|}{ Medidas } & \multicolumn{4}{|c}{ Grupo RB (T2) } & \multicolumn{3}{c}{ Grupo RN (T2) } \\
\hline & Média & DP & Média & DP & P \\
\hline Dist III-III (mm) & 34,90 & 2,86 & 35,82 & 2,38 & $0,216 \mathrm{~ns}$ \\
Dist V-V (mm) & 48,16 & 3,24 & 48,84 & 3,05 & $0,444 \mathrm{~ns}$ \\
Overjet (mm) & 4,00 & 2,56 & 2,52 & 1,36 & $0,020 *$ \\
\hline
\end{tabular}

Comparando-se as médias iniciais e finais (Tabela 7) das medidas oclusais nos grupos RB e RN observa-se que todas tiveram um aumento significante, exceto o overjet do grupo RN. A maxila mostrou crescimento transversal na região anterior e posterior nos dois grupos.

Tabela 7 - Comparação das medidas oclusais entre os tempos T1 e T2 nos grupos RB e RN, por meio do teste $\mathrm{t}$ pareado

\begin{tabular}{|c|c|c|c|c|c|c|c|c|c|c|}
\hline \multicolumn{6}{|c|}{ Grupo RB } & \multicolumn{5}{|c|}{ Grupo RN } \\
\hline \multirow[t]{2}{*}{ Medidas } & \multicolumn{2}{|c|}{ Inicial - T1 } & \multicolumn{3}{|c|}{ Final - T2 } & \multicolumn{2}{|c|}{ Inicial - T1 } & \multicolumn{2}{|c|}{ Final -T2 } & \\
\hline & Média & DP & Média & DP & $\mathbf{p}$ & Média & DP & Méda & DP & $\mathbf{p}$ \\
\hline Dist III-III(mm) & 32,12 & 2,0 & 34,89 & 2,86 & $<0,0001^{* * *}$ & 33,2 & 2,30 & 35,82 & 2,40 & $<0,0001 * * *$ \\
\hline Dist V-V(mm) & 46,71 & 2,63 & 48,16 & 3,24 & $<0,0001^{* * *}$ & 47,75 & 2,90 & 48,84 & 3,05 & $0,0006 * * *$ \\
\hline Overjet (mm) & 3,10 & 2,0 & 3,98 & 2,56 & $0,02 *$ & 2,31 & 1,06 & 2,52 & 1,36 & $0,47 \mathrm{~ns}$ \\
\hline
\end{tabular}

Os resultados das comparações da variação média das medidas oclusais nos dois momentos (T2-T1) entre os Grupos RB e RN, mostram que não há diferença estatística para distância intercaninos e intermolares e para o overjet (Tabela 8).

Tabela 8 - Comparação da variação das medidas oclusais (T2-T1) entre os grupos RB e RN, por meio do teste $t$ de Student

\begin{tabular}{c|ll|lcc}
\hline Medidas & \multicolumn{4}{|c|}{ T2-T1 (Grupo RB) } & \multicolumn{3}{|c}{ T2-T1 (Grupo RN) } & \\
& Média & DP & Média & DP & P \\
Dist III-III (mm) & 2,8 & 1,6 & 2,6 & 1,05 & $0,68 \mathrm{~ns}$ \\
Dist V-V (mm) & 1,3 & 1,2 & 1,1 & 1,30 & $0,55 \mathrm{~ns}$ \\
Overjet (mm) & 0,65 & 1,9 & 0,16 & 1,33 & $0,30 \mathrm{~ns}$ \\
\hline
\end{tabular}

$(\mathrm{mm})$ milímetro; ns=não significante; $\quad \mathrm{DP}=$ desvio padrão 
A Tabela 9 e a Figura 10 mostram as comparações das características oclusais entre os Grupos RB e RN no tempo T1 e a Tabela 10 e Figura 11, no tempo T2. Em T1 houve presença estatisticamente maior de mordida cruzada posterior no grupo RB. As demais características oclusais não apresentaram diferença estatisticamente significante. No tempo T2, somente o overbite foi estatisticamente diferente entre os grupos RB e RN. O grupo RN mostrou mais tendência à mordida profunda e o grupo RB ao overbite normal (Figura 11).

Tabela 9 - Comparação das características oclusais entre os grupos RB e RN no tempo T1, por meio do teste quiquadrado e Mann Whitney

\begin{tabular}{l|lll}
\hline Características & \multicolumn{1}{c}{ P } \\
Mordida aberta & $X^{2}$ calc. & 0,024 & $0,876 \mathrm{~ns}$ \\
Mordida cruzada & $X^{2}$ calc. & 11,1 & $0,0008^{* * *}$ \\
Rel. canino esq. + dir & U calc. & 1327 & $0,514 \mathrm{~ns}$ \\
PI. terminal $2^{\circ}$ mol. dec. esq.+ dir. & $X^{2}$ calc. & 2,0 & $0,360 \mathrm{~ns}$ \\
Overbite & $X^{2}$ calc. & 3,2 & $0,202 \mathrm{~ns}$ \\
\hline
\end{tabular}

*** $\mathrm{p}<0,001 ; \quad \mathrm{X}^{2}$ calc. $=$ Valor calculado do quiquadrado

ns=não significante ; $\quad U$ calc. = valor calculado do teste de Mann Whitney

Tabela 10 - Comparação das características oclusais entre os grupos RB e RN no tempo T2, por meio do teste quiquadrado e Mann Whitney

\begin{tabular}{l|lll}
\hline Características & \multicolumn{2}{c}{ P } \\
Mordida aberta & $X^{2}$ calc. 1,1 & $0,285 \mathrm{~ns}$ \\
Mordida cruzada & $X^{2}$ calc. 0,29 & $0,592 \mathrm{~ns}$ \\
Rel. canino esq. + dir & U calc. 1397 & $0,837 \mathrm{~ns}$ \\
Pl. terminal $2^{\circ}$ mol. dec. esq.+ dir. & $X^{2}$ calc. 1,4 & $0,505 \mathrm{~ns}$ \\
Overbite & $X^{2}$ calc. 9.9 & $0,007 * *$ \\
\hline
\end{tabular}

$* * \mathrm{p}<0,01 ; \quad \mathrm{x}^{2}$ calc. $=$ Valor calculado do quiquadrado

ns=não significante ; U calc. $=$ valor calculado do teste de Mann Whitney 


\section{T1 RB x T1RN}

A

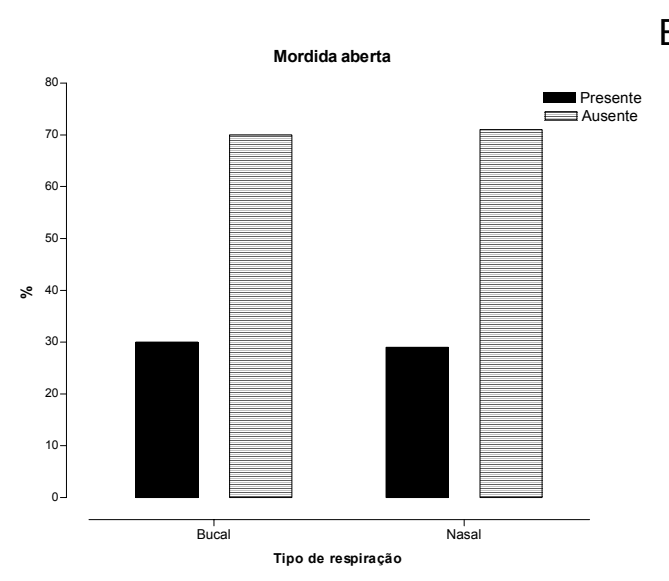

B

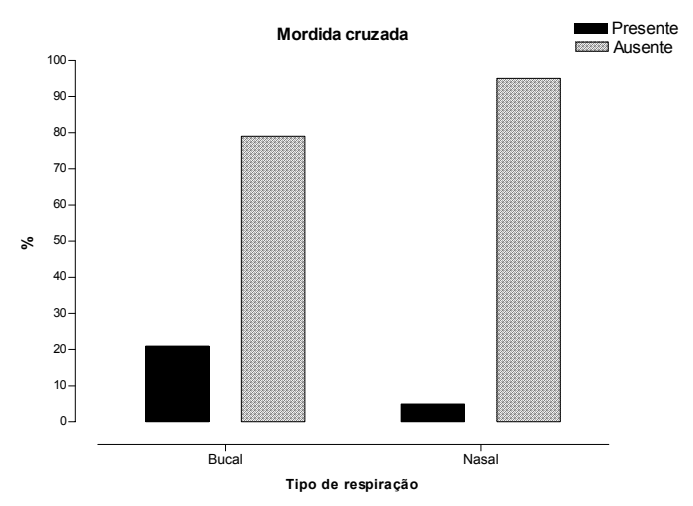

C

D
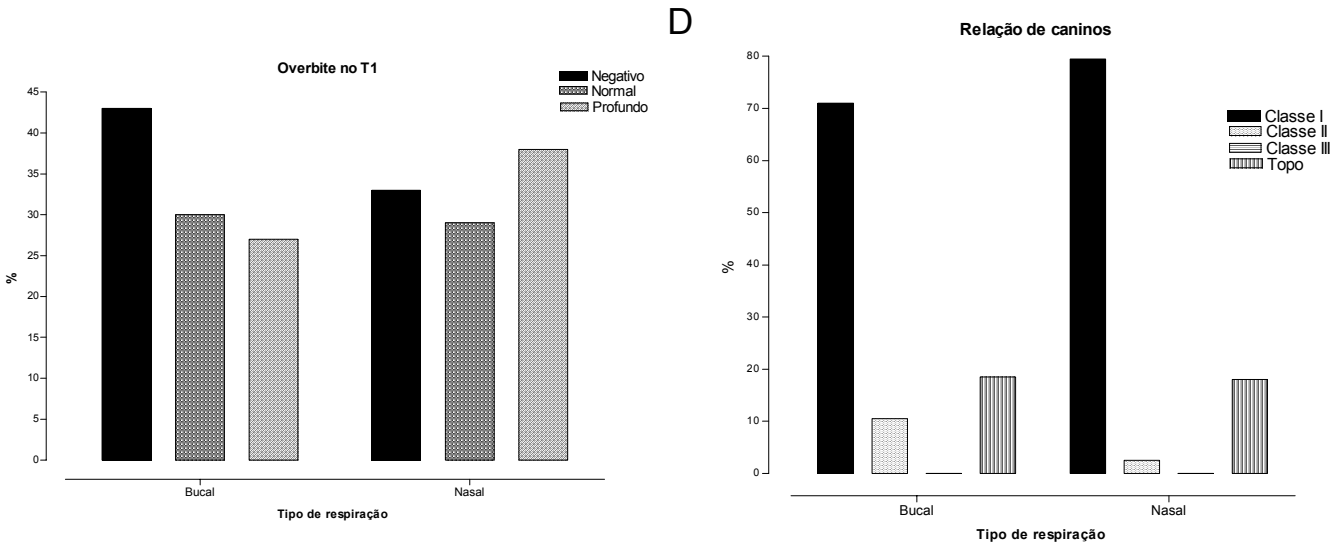

$\mathrm{E}$

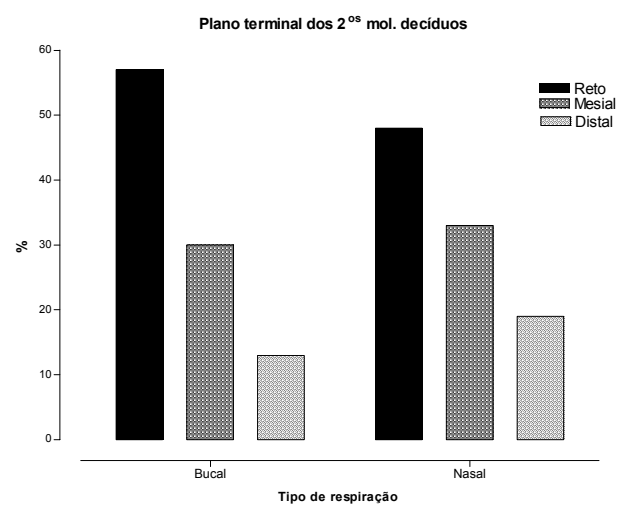

Figura 10 - Porcentagem de indivíduos segundo ausência e presença de mordida aberta (A), mordida cruzada(B), e em relação ao overbite (C), relação ântero-posterior de caninos decíduos direito e esquerdo (D) e plano terminal dos segundos molares decíduos direito e esquerdo (E), no tempo T1 nos grupos RB e RN. 


\section{T 2 RB x T2 RN}

A

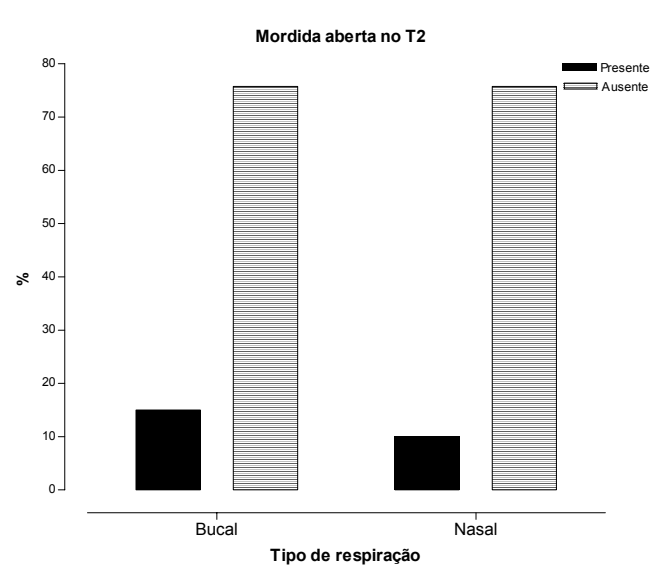

C

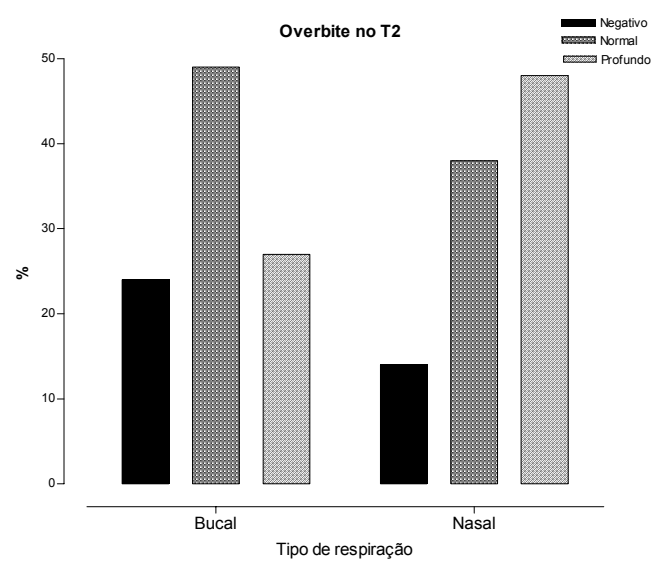

$\mathrm{E}$

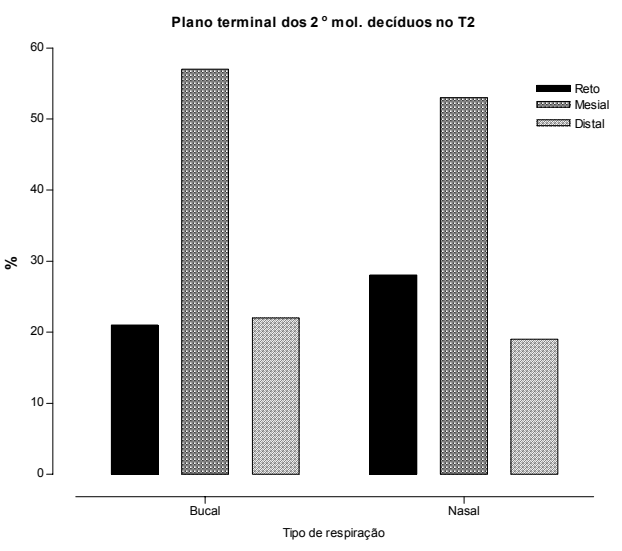

B

Mordida cruzadiano

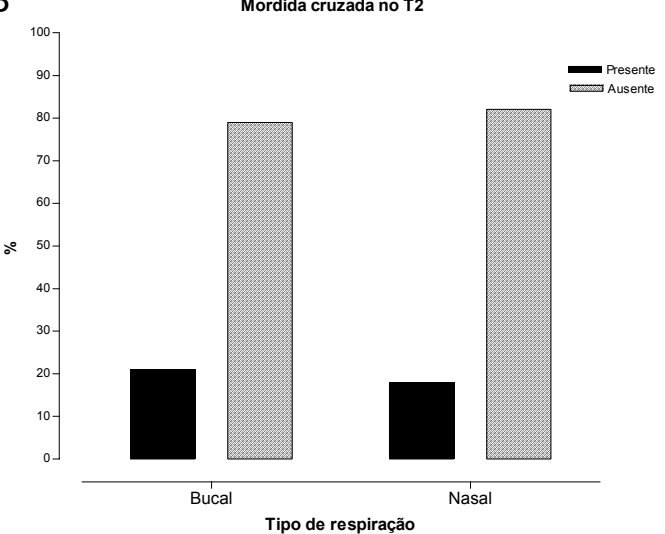

D

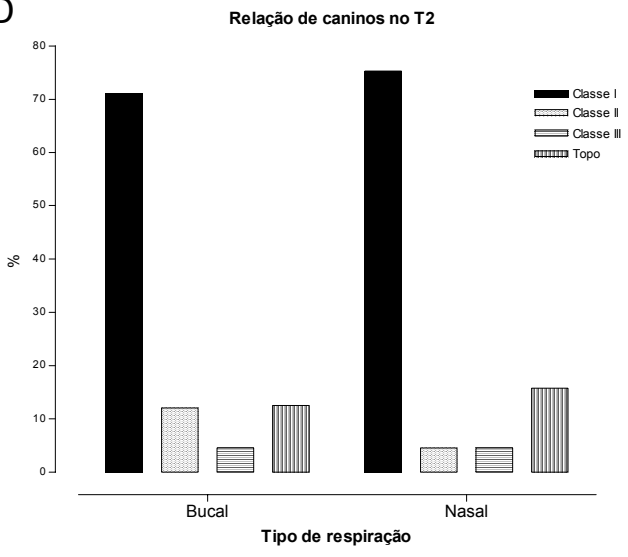

Figura 11 - Porcentagem de indivíduos segundo ausência e presença de mordida aberta (A), mordida cruzada (B), e em relação ao overbite (C), relação ântero-posterior de caninos decíduos direito e esquerdo (D) e plano terminal dos segundos molares decíduos direito e esquerdo (E), no tempo T2 nos grupos RB e RN. 
Ao se comparar as alterações nas características oclusais entre os tempos T1 e T2 nos grupos RB e RN (Tabela 11), em ambos foi encontrada diferença estatísticamente significante em relação ao plano terminal dos segundos molares decíduos direito e esquerdo e overbite. As demais características avaliadas como mordida aberta, mordida cruzada e relação de canino direito e esquerdo se comportaram de maneira estatisticamente semelhante em ambos os grupos. A relação de plano terminal dos segundos molares decíduos nos dois grupos apresentou-se na maioria com degrau mesial. No grupo RB overbite foi normal e profundo no grupo RN (Figuras 12 e 13).

Tabela 11 - Comparação das características oclusais entre os tempos T1 e T2 dentro de cada grupo, por meio do teste Mac-Nemar, Wilcoxon e Quiquadrado.

\begin{tabular}{|c|c|c|c|c|}
\hline \multirow[t]{2}{*}{ Características } & \multicolumn{2}{|c|}{ Grupo RB } & \multicolumn{2}{|c|}{ Grupo RN } \\
\hline & & $\mathbf{P}$ & & $\mathbf{P}$ \\
\hline Mordida aberta & $\mathrm{X}^{2}$ calc. 1,45 & $0,23 \mathrm{~ns}$ & $\mathrm{X}^{2}$ calc. 2,25 & $0,13 \mathrm{~ns}$ \\
\hline Mordida cruzada & $X^{2}$ calc. 0,16 & 0,68 ns & $X^{2}$ calc. 1,33 & $0,24 \mathrm{~ns}$ \\
\hline Rel. canino esq. + dir & W calc. 15 & $0,57 \mathrm{~ns}$ & W calc. -5 & $0,74 \mathrm{~ns}$ \\
\hline PL. terminal $2^{\circ}$ mol. Dec. esq. + dir. & $x^{2}$ calc. 27,2 & $<0,0001^{* * *}$ & $X^{2}$ calc. 9,9 & $0,007 * *$ \\
\hline Overbite & $X^{2}$ calc. 10 & $0,007 * *$ & $X^{2}$ calc. 18 & $0,0001 * * *$ \\
\hline
\end{tabular}

$* * \mathrm{p}<0,001 ; \quad * * * \mathrm{p}<0,0001 ; \quad$ ns=não significante

$\mathrm{X}^{2}$ calc. $=$ Valor calculado do quiquadrado ; $\mathrm{W}$ calc. $=$ Valor calculado do teste de Wilcoxon

Ao se comparar a variação das características oclusais entre os grupos RB e RN em função do tempo (Tabela 12), verificou-se que houve variação estatisticamente significante somente para mordida cruzada. Para melhor visualização dos dados, avaliar as figuras 12 e 13.

Tabela 12 - Comparação da variação das características oclusais (T2-T1) entre os grupos RB e RN, por meio do teste quiquadrado e Mann Whitney

\begin{tabular}{l|ll}
\hline Características & \multicolumn{1}{c}{ p } \\
\hline Mordida aberta & $\mathrm{X}^{2}$ calc. 1,2 & $0,761 \mathrm{~ns}$ \\
Mordida cruzada & $\mathrm{X}^{2}$ calc. 12 & $0,008^{* *}$ \\
Rel. canino esq. + dir & U calc. 1397 & $0,84 \mathrm{~ns}$ \\
Pl. terminal $2^{\circ}$ mol. dec. esq.+ dir. & $\mathrm{X}^{2}$ calc. 3,4 & $0,643 \mathrm{~ns}$ \\
Overbite & $\mathrm{X}^{2}$ calc. 5,9 & $0,311 \mathrm{~ns}$ \\
\hline
\end{tabular}

${ }^{* *} \mathrm{p}<0,01 ; \quad \mathrm{X}^{2}$ calc. $=$ Valor calculado do quiquadrado

ns=não significante ; $\quad U$ calc. = valor calculado do teste de Mann Whitney 


\section{T1 x T2 no RB e no RN}
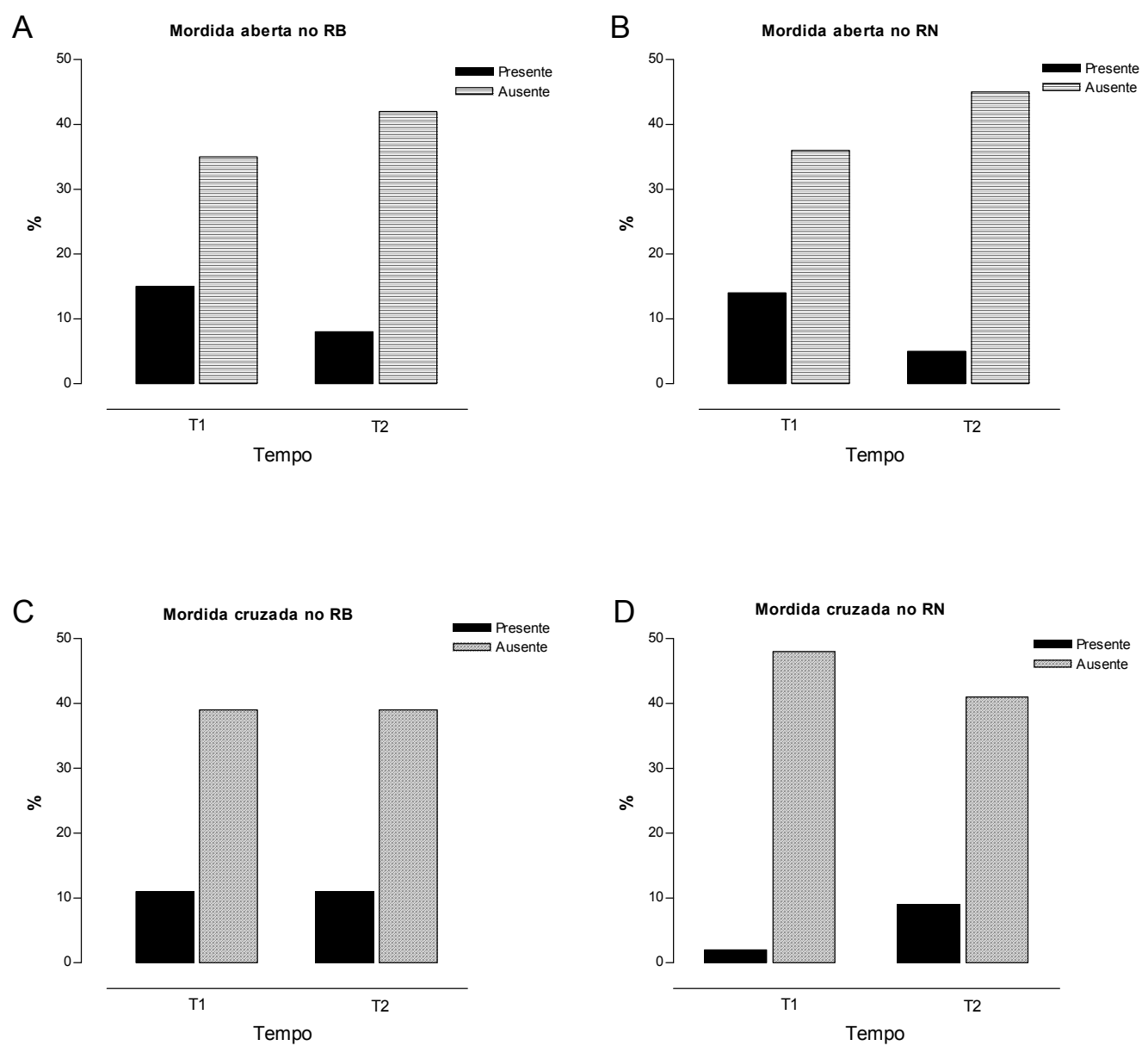

Figura 12 - Comparação da porcentagem de indivíduos segundo presença ou ausência de mordida aberta ( $A$ e B) e mordida cruzada ( e D) entre os tempos T1 e T2, nos grupos RB e RN. 


\section{T1 x T2 no RB e no RN}
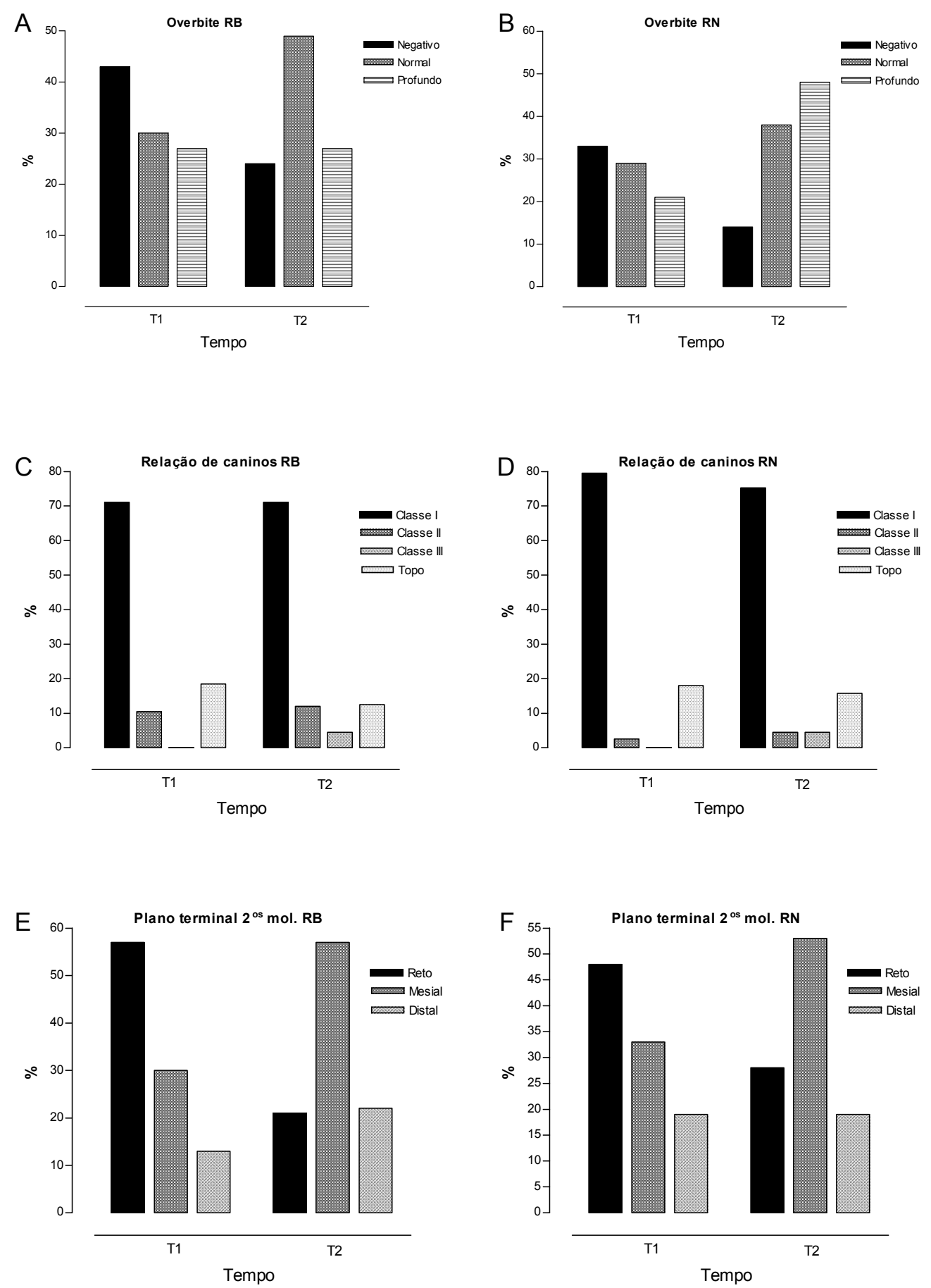

Figura 13 - Comparação da porcentagem de indivíduos em relação ao overbite (A e B), relação ânteroposterior de caninos decíduos direito e esquerdo ( $C$ e $D$ ) e plano terminal dos segundos molares decíduos direito e esquerdo ( $E$ e F) entre os tempos T1 e T2, nos grupos RB e RN. 



\section{Discussão}

Considera-se que, as impressões clínicas e avaliações subjetivas freqüentemente utilizadas, não são confiáveis para classificar o tipo de respiração do paciente (Vig et al., 1981; Hartgerink e Vig, 1989). As quantidades relativas de respiração nasal e/ ou bucal são impossíveis de serem medidas de modo adequado e diferencial apenas clinicamente (Diamond, 1980). Neste trabalho, diagnóstico preciso da respiração para classificação das crianças como respiradoras bucais e nasais foi realizada por exames otorrinolaringologicos que consistiram em avaliação clínica, com exame físico através da oroscopia, rinoscopia anterior e otoscopia, e avaliação adenoideana realizada por meio da radiografia lateral.

Para avaliação da adenóide utilizou-se o método radiológico de Cohen e Konak (1985). Este método tem grande correlação com o de Fujioka et al. (1979), e é considerado fácil e tão fidedigno quanto outros métodos. Os autores ressaltam que é o tamanho da coluna aérea, e não o da adenóide, que possui correlação com os sintomas obstrutivos respiratórios, principalmente ao nível da coana, de tal modo que, quando a coluna aérea se apresenta mais estreita que o palato mole, iniciam-se os sintomas obstrutivos, que serão mais acentuados quanto maior for o estreitamento da coluna aérea.

Para classificação de hipertrofia de tonsila palatina, utilizou-se na oroscopia, os critérios de Brodsky \& Kock (1992). A remoção cirúrgica das tonsilas palatinas foi indicada quando havia amigdalites de repetição associada, e classificação de grau 3 ou grau 4, isto é, obstrução maior que $50 \%$ do espaço entre pilares anteriores.

\section{1) Avaliação das medidas cefalométricas}

Comparando-se a média das medidas cefalométricas entre os Grupos RB e RN no momento T1, as medidas SN.GoGn, PP.PM, ArGo.GoMe, BaN.PtGn, S-Go, ArGo se mostraram diferentes estatisticamente. As medidas SN.GoGn e PP.PM estão relacionadas com a inclinação da mandíbula, que mostra rotação no sentido horário, com maior inclinação do plano mandibular, apresentando médias maiores nos pacientes do grupo RB.

Esse resultado também foi encontrado por Bresolin et al. (1983), Faria (2000), e Lessa et al. (2005) que avaliaram crianças com idades maiores que 6 anos. 
Zucconi et al. (1999), demonstraram que crianças com ronco e apnéia obstrutiva do sono (AOS) apresentavam valores aumentados dos ângulos craniomandibulares, ângulo entre o plano oclusal e o plano mandibular, inclinação posterior no plano mandibular, indicando predomínio do crescimento vertical. Do mesmo modo, Kawashima et al. (2002), Zettergren-Wijk et al. (2006) também verificaram alteração na inclinação do plano mandibular em respiradores bucais, mesmo em crianças mais jovens, até 6 anos de idade, quando comparados com respiradores nasais.

A abertura do ângulo da mandíbula também foi demonstrada morfologicamente, pelo maior grau de inclinação do ramo com o corpo da mandíbula, encontrado na medida do ângulo ArGo.GoMe no grupo RB em T1. Estes achados já haviam sido confirmados por Ricketts (1968), Bresolin et al. (1983, 1984) e Ung et al. (1990) que encontraram maior divergência dos planos palatal e mandibular (PP.PM) e ângulo goníaco mais obtuso (ArGo.GoMe) nos pacientes respiradores bucais. Cheng et al., em 1988, associaram a forma dolicofacial a uma face mais longilínea e ângulo do plano mandibular aumentado.

No entanto, Sabatoski et al. (2002), não encontraram nenhuma correlação estatisticamente significativa $(p<0,05)$ entre os grupos de respiradores nasais e bucais quanto ao ângulo goníaco e inclinação do plano mandibular, divergindo dos resultados encontrados no presente estudo.

O eixo facial (BaN.PtGn) mostrou comportamento inverso entre os grupos, de tal modo que, em T1,as médias foram maiores no grupo RN, ressaltando que o padrão morfológico nos respiradores nasais tende ao padrão mais mesofacial, enquanto, nas crianças respiradoras bucais, o tipo morfológico indica tendência ao padrão dolicofacial. Segundo Defabijanis (2003), muitos estudos têm demonstrado como a obstrução das vias aéreas tem importante influência na forma facial e é freqüentemente associada ao padrão de crescimento dolicocefálico. Esses resultados se assemelham aos de McNamara (1981), Joseph (1982), Klein (1986), Smith e Gonzales (1989), Fields et al. (1991), Tourné (1991) e Mocellin et al. (2000), onde os pacientes respiradores bucais apresentaram padrão dolicofacial; enquanto os respiradores nasais, em sua grande maioria, eram mesofaciais. Motonaga et al. (2000) avaliando alterações no sistema estomatognático de crianças respiradoras bucais de 3 a 10 anos encontraram características sugestivas de dolicocéfalo, em 64,42\% delas. Lima et al. (2005) constataram valores menores na medida do eixo facial BaN-PtGn, em 76,66\% dos pacientes respiradores bucais entre 7 e 12 anos de idade. 0 padrão dolicofacial foi predominante $(70 \%)$, mas não puderam determinar se este padrão facial foi causa ou conseqüência da respiração bucal. Os autores confirmaram a existência de dependência entre obstrução nasal e tipo facial. 
Linder-Aronson (1970) observou que obstrução nasal devido à hipertrofia de tonsilas faríngeas ocorre com maior freqüência entre crianças dolicocefálicas e com menor tamanho de nasofaringe. Se o indivíduo é geneticamente predisposto à morfologia esquelética facial desfavorável, particularmente por crescimento vertical excessivo da face, a respiração bucal pode ser fator aditivo no desenvolvimento de uma maloclusão indesejável (Subtelny, 1980). Se ocorrer uma compensação da função muscular associada à respiração bucal, extensão da cabeça, e abaixamento da postura mandibular, isso poderá ser determinante na morfologia craniofacial em indivíduos em crescimento que sofrem obstrução nasal por um longo período de tempo (Ribeiro et al., 2004; Cuccia et al., 2008). Kawashima (2002) mostrou, já em crianças pré-escolares, predisposição às desordens respiratórias, inclusive diferenciando 0 sexo. Os meninos mostraram mais fatores de risco esqueletais, com altura facial ântero- inferior aumentada, e as meninas mostraram o espaço aéro nasofaringeano mais estreito.

Opiniões controversas foram divulgadas em estudo mais recente. Bianchini et al. (2007) não comprovaram a existência de relação entre respiração oral e tipo facial, empregando índices antropométricos, em 119 adolescentes. No entanto, as medidas foram feitas diretamente na face dos pacientes para determinar o tipo facial, obtido pela relação entre largura e altura da face. Tanto nos respiradores bucais como nasais, o padrão mais encontrado foi mesofacial.

Após 28 meses de acompanhamento, comparando-se as medidas cefalométricas no momento T2 entre os Grupos RB e RN, foi encontrada diferença estatisticamente significante somente na medida BaN.PtGn. As diferenças cefalométricas previamente encontradas no momento $T 1$, foram compensadas após a mudança do padrão respiratório das crianças do grupo RB. Porém, os resultados ainda mostram que existe tendência ao padrão morfológico dolicofacial no grupo RB, quando comparados com o grupo RN. Apesar disso, somente o grupo RB apresentou aumento significante no ângulo do eixo facial (BaN.PtGn) entre T1 e T2, mostrando que as faces tornaram-se mais proporcionais em relação à altura e profundidade. Kerr et al. (1987), evidenciaram que as diferenças angulares notadas pré-cirurgicamente entre os grupos da adenoidectomia e controle, tenderam para normalidade com 5 anos de pós-operatório em crianças entre 8 e 13 anos de idade. O grupo dos respiradores bucais se tornou menos dolicocefálico nas características faciais gerais. Mudanças no modo respiratório parecem influenciar na posição espacial da mandíbula, resultando em direção de crescimento mais anterior. Certos padrões hereditários estão 
mais predispostos à respiração bucal do que outros padrões e vice-versa (Subtelny, 1980). Crianças com predisposição a faces longas são mais severamente afetadas quando ocorre maior duração de respiração oral. Freitas et al., em 2006, encontraram maior estreitamento da via aérea faringeana superior em individuos com maloclusão de Classe I e II e padrão de crescimento vertical do que em grupos com o padrão de crescimento normal. Muitas destas tendências são visíveis em crianças novas, inclusive aos 3 anos de idade, mas são mais comumente detectadas a partir dos 5 anos. Diagnóstico precoce e tratamento da desordem pediátrica nasal obstrutiva, particularmente em crianças com evidência de mudanças precoces craniofaciais e dentoalveolares parecem ser justificáveis (Principato, 1991; Valera et al., 2003). 0 impacto deletério das conseqüências da obstrução no desenvolvimento craniofacial se completa na puberdade. Conseqüentemente, a oportunidade para intervenção com sucesso é limitada.

Quanto às medidas cefalométricas lineares S-Go e Ar-Go, suas médias foram maiores no grupo RN do que no grupo RB em T1, indicando menor altura facial posterior e menor altura do ramo mandibular nas crianças que apresentavam respiração bucal. Zucconi et al. (1999) e Lessa et al. (2005) também encontraram nos pacientes respiradores bucais menor altura facial posterior, inclusive em crianças com menos de 6 anos de idade. Já Bresolin et al. (1983;1984) e Lima et al. (2005) não encontraram alterações na altura facial posterior dos pacientes respiradores bucais. No momento T2, as medidas S-Go e Ar-Go se encontraram semelhantes ao grupo RN. Esses mesmos resultados foram observados no trabalho de Zettergreen-Wijk et al. (2006) ao avaliarem crianças com Síndrome da Apnéia Obstrutiva (SAO) com média de 5,6 anos de idade. Inicialmente a altura facial póstero-inferior mostrou-se diminuida, mas cinco anos pós-adenoidectomia não houve diferenças estatísticas significantes entre os grupos comparados.

A altura facial anterior analisada através das medidas ( $\mathrm{N}-\mathrm{Me}, \mathrm{N}-\mathrm{ENA}$, ENA-Me) teve comportamento semelhante em T1 e T2 nos grupos RB e RN. Todas as medidas verticais lineares anteriores e posteriores (N-Me, N-ENA, ENA-Me, S-Go, S-Ar, Ar-Go) apresentaram aumento estatisticamente significante nos valores médios medidos em ambos os grupos entre T1 e T2. Isso indica que ocorreu crescimento vertical anterior e posterior da face nas duas amostras, e em T2 essas medidas se apresentaram estatisticamente semelhantes. Em muitos estudos foi observada correlação significativa entre a resistência nasal e aumento da altura facial anterior (Bresolin et al., 1983; Sassouni et al., 1982; Trask et al., 1987; Ung et al., 1990; 
Sabatoski et al., 2002), principalmente na região ântero-inferior (Lessa et al., 2005). Em contrapartida, Hartgerink e Vig, em 1989, não encontraram correlação entre alterações na resistência nasal e altura facial.

Autores como Zucconi et al. (1999) e Lessa et al. (2005) relataram que houve aumento da altura facial anterior e redução da altura facial posterior nos respiradores bucais. Zettergren-Wijk et al. (2006), encontraram a altura facial ânteroinferior aumentada e a base craniana anterior encurtada, nas crianças com SAO onde o tratamento foi adenotonsilectomia. Cinco anos pós-tratamento, não houve diferenças estatísticas significantes entre os grupos, exceto para as medidas da base anterior do crânio e nariz que eram menores no grupo experimental. Entretanto, a altura facial ântero-inferior ainda se apresentava maior nas crianças com SAO.

Com resultados semelhantes ao do presente trabalho, Kerr e colaboradores (1989), não encontraram diferenças na altura facial anterior, 5 anos após adenoidectomia. $\mathrm{O}$ crescimento do ramo mandibular e do processo condilar dos pacientes que foram submetidos à adenoidectomia, mostraram-se maiores que o do grupo controle, provavelmente devido à alteração na posição da língua e auto-rotação da mandíbula (Linder-Aronson, 1979). Segundo Woodside et al. (1991), para que ocorra diminuição no ângulo do plano mandibular em relação aos planos horizontais da base craniana, ou seja, rotação da mandíbula no sentido anti-horário, é necessário mais crescimento na altura posterior da face e na altura do ramo do que na região anterior.

Ao se avaliar o comportamento das medidas cefalométricas, em média, 28 meses após a intervenção cirúrgica, pode-se constatar que as medidas SN.GoGn, PP.PM, SNGn e BaN.PtGn, tiveram mudanças significantes somente no Grupo RB entre T1 e T2, aproximando-se dos valores dos ângulos encontrados nas medidas do grupo RN. Verificou-se que a mudança no padrão respiratório resulta em menor inclinação do plano mandibular com rotação no sentido anti-horário, direção de crescimento da face mais horizontal e padrão facial com tendência mesocefálico. Considera-se que em idades precoces, se o padrão respiratório for modificado, o organismo responde positivamente resultando num crescimento e desenvolvimento do sistema estomatognático mais próximo do normal. Após a adenoidectomia, a mandíbula cresceu numa direção mais horizontal segundo relatos de Linder-Aronson (1986), Behlfelt et al. (1990), Woodside et al. (1991), Agren et al. (1998), Arun et al. (2003), Zettergren-Wijk et al. (2006).

O ângulo goníaco (ArGo-GoMe) teve modificação significante nos dois grupos entre os momentos T1 e T2. No grupo RB houve diminuição dos valores médios do ângulo $\left(-3,5^{\circ}\right)$, e no grupo RN um aumento $(2,9)$. Os valores em média se tornaram 
mais próximos. Como já visto, estas medidas no tempo T2 se mostraram estatisticamente semelhantes entre os dois grupos estudados. Do mesmo modo, Hulcrantz e colaboradores (1991), relataram que dois anos pós-tonsilectomia houve redução de 3,70 nesse ângulo. Os pacientes que apresentavam menos que seis anos de idade, tenderam a apresentar crescimento mais próximo do normal.

Quando a obstrução severa das vias aéreas respiratórias é diagnosticada e tratada numa idade precoce, alteração na morfologia dentofacial pode ser conseguida. Ao avaliarem crianças com aproximadamente 6 anos de idade, Agren e colaboradores (1998), suportaram a hipótese de que obstrução das vias aéreas tem influência no desenvolvimento craniofacial, uma vez que a remoção cirúrgica da obstrução aérea foi seguida de melhora significante no padrão esquelético da face, nas arcadas dentárias e nos sintomas apresentados pelos pacientes (Bahadir et al., 2006).

De acordo com Peltomäki (2007), as crianças com Apnéia Obstrutiva do Sono, apresentaram secreção anormal do hormônio de crescimento noturno (GH) e impedimento de crescimento somático, o qual é normalizado após a adenotonsilectomia. Foi postulado que, a mudança da estrutura craniofacial antes e após tonsilectomia, não é causada somente pelo mecanismo de alteração no equilíbrio muscular, posição da cabeça e da língua, resultante da mudança do modo respiratório, mas também por uma complexa seqüência de eventos epigenéticos. Devido à secreção noturna anormal de hormônio de crescimento e seus mediadores, em crianças com obstrução nasal, o crescimento do ramo mandibular é menor do que em crianças saudáveis (Fosberg et al., 2002). Após a normalização do status hormonal, o crescimento do ramo é realçado por maior intensidade de formação de osso endocondral na cartilagem condilar e/ou por osso aposicional de crescimento no bordo inferior da mandíbula na área de inserção muscular. Isso poderia, em parte, explicar a evidente aceleração do crescimento da mandíbula e alteração na sua direção de crescimento, após adenotonsilectomia, e conseqüente mudança no modo respiratório.

Ao analisar cada grupo separadamente, 28 meses após procedimento o cirúrgico observou-se que a medida SNA apresentou variação de T1 para T2 no grupo $\mathrm{RB}$, com leve aumento no valor da média $\left(0,9^{\circ}\right)$, mas entre os grupos, não se mostrou diferente em nenhum dos momentos. Verificou-se também aumento nos valores de SNB $\left(0,8^{\circ}\right)$, indicando crescimento mandibular nesse período de avaliação. Entretanto, não foi observada diferença estatísticamente significante no crescimento maxilar e mandibular após tonsilectomia. Como resultado do crescimento anterior da maxila e da 
mandíbula, nos respiradores bucais, o ANB não se alterou no período avaliado. Na literatura muitos resultados mostraram-se controversos. Trotman et al. (1997), encontraram em pacientes com tonsilas palatinas hipertrofiadas, posição mais anterior da maxila e conseqüentemente o SNA aumentado. Woodside et al., em 1991, estudaram a quantidade e direção de crescimento maxilar e mandibular, cinco anos pós- adenoidectomia, para correção de obstrução aérea severa. Os meninos mostraram tendência de crescimento maior da maxila, porém, não foi detectada diferença na direção do crescimento maxilar entre os pacientes submetidos à adenoidectomia e o grupo controle. No estudo de acompanhamento pós-cirúrgico realizado em crianças pré-escolares, por Zettergren-Wijk et al. (2006), não se encontrou diferença em relação ao prognatismo maxilar, após cinco anos de tratamento realizado. Entretanto, Santos-Pinto et al. (1993) e Lima et al. (2005) observaram a maxila dos respiradores bucais bem relacionada com tendência à retrusão em relação à base do crânio. Sassouni et al. (1982) e Bresolin et al. (1983) associaram crianças respiradoras bucais com rinite, a uma incidência de retrognatimo maxilar devido aos valores mais reduzidos do SNA.

Não se encontrou correlação do modo respiratório com as medidas horizontais da face (SNB e ANB) em nenhum dos dois grupos, reforçando o conceito de que o tipo de respiração não influencia o padrão de crescimento no plano horizontal dos maxilares, confirmando as evidências de Sabatoski et al., 2002. No entanto, uma posição mais retrognática da mandíbula foi encontrada por vários autores (LinderAronson, 1970, 1979; Santos-Pinto et al., 1993; Kluemper et al., 1995). Bresolin et al. (1983, 1984) verificaram que maxila e mandíbula foram mais retrognáticas nos respiradores bucais, apesar de a relação ântero-posterior dos maxilares ter sido mantida. Ung et al. (1990) e Woodside e Linder-Aronson (1991), descreveram que, a respiração bucal mantida por um período prolongado, pode ser fator etiológico para 0 desenvolvimento de maloclusão de classe II. Kerr et al. (1987) constataram que os pacientes respiradores bucais, no pré operatório de adenoidectomia, apresentavam o ângulo SNB significantemente menor. No período pós-cirúrgico, essa medida angular mostrou-se estatisticamente semelhante aos pacientes do grupo controle. Trotman et al. (1997) e Sousa et al. (2005) concluíram que tonsilas palatinas hipertrofiadas estão associadas com posição mais anterior de maxila e mandíbula, e, conseqüentemente, com SNA e SNB aumentado. 


\section{2) Avaliação das características oclusais}

Os resultados dos testes estatísticos realizados para avaliar a existência de associação entre algumas características oclusais com a mudança no padrão respiratório, indicaram não existir semelhança estatística na relação ântero-posterior de canino, mordida aberta e distância intercaninos.

A distância intercaninos se apresentou semelhante entre os grupos RB e RN, sofrendo aumento, em média, proporcional nos dois grupos de T1 para T2. A distância intermolares em T1, apresentou valores menores, em média, no grupo dos $\mathrm{RB}$, indicando estreitamento transversal na região posterior da maxila, comparando-se com o grupo dos RN. Porém, em T2, os dois grupos se mostraram estatísticamente semelhantes, havendo uma compensação na largura intermolares nos respiradores bucais após a intervenção cirúrgica. Trask e Shapiro em 1987, não observaram diferença estatisticamente significante entre os grupos de crianças respiradoras bucais alérgicas e não alérgicas de 5 a 14 anos de idade, quanto à classificação de Angle e quanto ao relacionamento transversal dos arcos dentários. Linder-Aronson (1979) observou no grupo experimental que um ano após a tonsilectomia, aumentou a largura entre os primeiros molares superiores. Após cinco anos, a normalização dos arcos pôde ser constatada, assemelhando-se a média do grupo controle.

Santos-Pinto et al. (1993) observaram tendência à redução da distância intercaninos e intermolares superiores quando o espaço nasofaringeano encontrava-se reduzido. O arco inferior demonstrou não ser afetado transversalmente com as dimensões do espaço nasofaringeano. Paul e Nanda (1973) encontraram medidas da largura do arco maxilar menores no grupo dos respiradores bucais. Entretanto, somente a largura intermolar foi considerada significante ao nível de 5\%. Com relação à largura do arco mandibular, também não houve diferenças significantes.

Agren et al. (1998) mostraram que após 1 ano de controle, crianças com 6 anos de idade, em média, submetidas à adenotonsilectomia por respiração noturna obstrutiva, apresentaram em média, aumentos de $0.6 \mathrm{~mm}$ na largura entre os segundos molares decíduos. Inicialmente, as crianças apresentaram estreitamento do arco superior e alta freqüência de mordida cruzada lateral em comparação com crianças normais, sem sinais de obstrução das vias aéreas superiores. Após a cirurgia, as condições ortodônticas revelaram mudanças significantes, com auto-correção da mordida cruzada lateral. A distância entre os segundos molares decíduos do grupo RB neste estudo, aumentou em média $1,3 \mathrm{~mm}$ durante o período de acompanhamento, compensando a diferença significante encontrada no primeiro momento (T1). 
No presente estudo, o grupo RB, apresentou maior número de crianças com mordida cruzada em relação ao grupo RN no tempo T1, antes da cirurgia. No momento T2, as amostras se mostraram semelhantes, à custa do aumento de crianças com mordida cruzada no grupo RN, e do aumento da largura na distância intermolares nos respiradores bucais. A variação significante que ocorreu foi no grupo RN, e não no grupo RB, divergindo de muitos resultados encontrados na literatura. Isso pode ser justificado pela erupção dos primeiros molares permanentes em mordida cruzada, alterando a oclusão.

Linder- Aronson (1979) descreveu como típica a dentição de um respirador bucal que apresenta estreitamento do maxilar superior com mordida cruzada e tendência a mordida aberta. Zucconi et al. (1999) e Lima et al. (2005) avaliaram oclusão de pacientes com obstrução das vias aéreas superiores e verificaram presença de mordida cruzada de forma significante. Oulis et al. (1994) também mostraram um grande número de mordida cruzada posterior, tanto na dentição cruzada posterior não tinham história de sucção de chupeta ou dedo.

Hulcrantz et al. (1991) avaliaram crianças de 3 a 15 anos de idade antes e depois da tonsilectomia e verificaram grande incidência de maloclusão, especialmente de mordidas abertas e cruzadas, antes da cirurgia. Dois anos após a cirurgia, 50 a $65 \%$ das mordidas cruzadas posteriores e anteriores foram normalizadas. Os melhores resultados foram observados em crianças operadas antes dos seis anos de idade.

Com relação à mordida aberta anterior não houve diferença significante em nenhum momento, entre os grupos RB e RN. Os trabalhos de Principato (1991), Melsen et al. (1987) e Btzenberger et al. (1999) comprovaram maior freqüência de mordida aberta em respiradores bucais, diferindo dos resultados encontrados neste estudo. No grupo de 22 crianças suecas avaliadas por Hulcrantz et al. (1991), treze crianças apresentavam mordida aberta anterior, antes de serem submetidas à adenotonsilectomia ou somente tonsilectomia. Dois anos após a cirurgia, 77\% das mordidas abertas foram normalizadas.

A relação ântero-posterior dos arcos dentários mensurados por meio da relação de caninos e do plano terminal dos segundos molares decíduos, também não está sujeita à interferência do tipo de respiração, corroborando os achados de Ung et al. (1990) e Jabur et al. (1997). No presente estudo, em T1, a maioria dos pacientes dos grupos RB e RN apresentaram plano terminal dos segundos molares decíduos reto e relação de caninos em Classe I. Em T2, mais de 50\% dos planos terminais eram 
mesiais e mais de $60 \%$ das relações caninos direito e esquerdo se mantiveram em Classe I nos dois grupos. A alteração que o plano terminal dos segundos molares decíduos sofreu de T1 para T2 nos dois grupos, foi estatisticamente significante. Podese afirmar que houve alteração do plano terminal reto presente na maioria das crianças em T1, para degrau mesial em T2, provavelmente devido à erupção dos primeiros molares permanentes que promovem a migração fisiológica dos molares decíduos, fechando os espaços primatas inferiores entre caninos e os primeiros molares decíduos, resultando na alteração do plano terminal dos segundos molares decíduos e conseqüentemente no estabelecimento da relação dos primeiros molares permanentes em Classe I. No estudo de Hulcrantz et al. (1991), a relação sagital também observada em modelos de estudo, antes e depois da desobstrução cirúrgica das vias aéreas, não apresentou diferença estatisticamente significante.

Lima et al. (2005) encontraram em crianças respiradoras bucais e nasais de 7 a 12 anos, freqüências iguais de classe I, classe II e classe III de molares, indicando que maloclusão é independente da presença ou não de obstrução nasal. $A$ classe I foi a maloclusão mais encontrada nos dois grupos, confirmando com os resultados aqui encontrados. Bresolin et al. (1983) também não encontraram diferença significativa na prevalência de maloclusões classe I e classe II de Angle, entre os respiradores bucais e nasais. No entanto, alguns estudos mostram dados significantes na associação entre respiração bucal e maloclusão de classe II dentária (Paul e Nanda, 1973) ou respiração bucal e maior incidência de oclusão distal (Moffatt, 1963; Melsen et al., 1987).

A relação ântero-posterior medida pelo overjet, não foi diferente entre os dois grupos estudados em T1, mas em T2 os grupos se mostraram diferentes estatisticamente. Foi observado um aumento significante no overjet do grupo RB entre T1 e T2, coincidindo também com o aumento do SNA. O grupo RN praticamente não mostrou alteração no overjet nos dois momentos avaliados.

A relação vertical entre os incisivos, medida através do overbite, se mostrou estatisticamente semelhante entre os dois grupos em T1. Porém, observando os gráficos nota-se que o grupo RB (43\%) apresentava uma tendência ao overbite negativo maior que o grupo RN (33\%). No momento T2, houve alteração significante comparando-se os dois grupos, onde a maior parte dos pacientes do grupo RB apresentou tendência ao overbite normal (49\%) e no grupo RN ao overbite profundo (48\%). Diminuiu a tendência ao overbite negativo, após a cirurgia. Na análise vertical 
do trabalho de Hulcrantz et al. (1991) somente a presença de overbite negativo sofreu modificação significante entre os grupos, na fase pré e pós- adenoidectomia.

Bresolin et al. (1983, 1984), comparando grupos de respirador bucal e nasal, não encontraram diferenças quanto ao overbite. Cheng et al. (1988) declararam que o overbite era menor nos respiradores bucais. Contudo, Paul e Nanda (1973) notaram que os respiradores bucais, geralmente, têm alta incidência de maloclusões como overbite acentuado.

Torna-se importante salientar que os pacientes que mantiveram o padrão respiratório bucal por muito tempo e acima dos oito anos de idade, mostraram alterações na morfologia facial, nas características oclusais e no padrão facial bem distintas. Com a desobstrução das vias aéreas, através da adenotonsilectomia, observa-se a normalização de alterações faciais dentoesqueléticas, musculares e funcionais, porém com algumas limitações. Nota-se que os pacientes que tiveram a desobstrução das vias aéreas mais precocemente, mudando o padrão respiratório para nasal, em média até seis anos de idade, apresentam prognóstico mais positivo.

As alterações encontradas nas características faciais e na oclusão entre crianças respiradoras bucais e respiradoras nasais são menores antes dos seis anos de idade, comparando-se com crianças acima dessa faixa etária. Evidencia-se principalmente a posição espacial da mandíbula alterada, com tendência a rotação no sentido horário, direção de crescimento predominantemente vertical e região posterior da mandíbula e da face com encurtamento. Dois anos após a cirurgia, todas as medidas cefalométricas que inicialmente estavam alteradas principalmente em relação à mandíbula, se encontram normais, comparadas com as crianças do grupo controle, apesar de ainda persistir uma tendência ao padrão dolicofacial. Nesse período ativo de crescimento, as seqüelas poderão ser sanadas com a mudança do padrão respiratório.

Deve-se lembrar que somente permaneceram na avaliação as crianças do grupo RB, que não apresentaram recidiva da hipertrofia da tonsila faríngea após o procedimento cirúrgico. Vários fatores podem ser considerados responsáveis pela continuidade da respiração bucal, como a presença da rinite alérgica atuando no sentido de promover a recidiva da hipertrofia da tonsila faríngea, a persistência do hábito de respirar pela boca, indicando a necessidade de tratamento fonoaudiológico, e a própria característica esquelética dos dolicofaciais, com dimensões reduzidas na região posterior da face.

Um aspecto a ser considerado está na idade em que a cirurgia deve ser realizada para promover influências mais favoráveis no crescimento facial e 
desenvolvimento da oclusão. No presente estudo, foi efetuada por volta dos 3 a 4 anos, com resultados excelentes sobre as características oclusais e esqueléticas, resgatando o padrão de crescimento normal para esses pacientes respiradores bucais submetidos a remoção cirúrgica das tonsilas faríngea e/ou palatinas. Entretanto, seria interessante avaliar os efeitos do procedimento cirúrgico efetuado mais tarde, na dentição mista, ou seja, após os 6 anos de idade. 
2 


\section{CONCLUSÃo}

Os resultados deste estudo permitiram concluir:

\section{Em relação ao padrão morfológico da face}

1. A comparação entre os grupos, evidenciou que:

1.1. No momento $T 1$, houve diferença nos dois grupos estudados no que se refere aos seguintes aspectos:

- maior inclinação do plano mandibular em relação à base craniana e plano palatal (SN.GoGn; PP.PM) nos respiradores bucais

- ângulo goníaco mais obtuso (ArGo.GoMe) nos respiradores bucais

- altura do ramo da mandíbula (Ar-Go) e altura posterior da face (S-Go) diminuidas nos respiradores bucais quando comparados aos nasais

- os respiradores bucais foram mais propensos a apresentar o tipo morfológico dolicofacial (BaN.PtGn) do que os respiradores nasais

1.2 No momento T2, a diferença entre os grupos foi observada no:

- padrão morfológico da face, pois os respiradores nasais apresentaram -se mesofaciais e os respiradores bucais, dolicofaciais

2. Ao analisar cada grupo separadamente, vinte e oito meses, em média, após o procedimento cirúrgico, foram observadas as seguintes alterações:

- Nos respiradores bucais, houve alteração na direção do crescimento da face e inclinação do plano mandibular no sentido anti-horário, com diminuição dos valores de SN.GoGn, PP.PM, SNGn, ArGo.GoMe e aumento de BaN.PtGn

- as medidas verticais lineares (N-Me, N-ENA, ENA-Me, S-Go, S-Ar, ArGo) aumentaram mostrando que houve crescimento vertical anterior e posterior da face, nos respiradores bucais e nasais 


\section{Em relação às características oclusais}

1. A comparação entre os grupos, evidenciou que:

1.1. No momento $T 1$, houve diferença nos dois grupos estudados no que se refere aos seguintes aspectos:

- Verificou-se maior número de crianças respiradoras bucais com mordida cruzada

- Os respiradores bucais apresentaram menor distância intermolares

1.2 No momento T2, foi constatado que:

- o overjet foi maior nos respiradores bucais

- o overbite apresentou-se diferente nos dois grupos: normal nos respiradores bucais e profundo nos respiradores nasais

- as características oclusais como mordida aberta, mordida cruzada, relação de caninos e plano terminal dos segundos molares decíduos, e distância intermolares se mostraram semelhantes, em ambos os grupos

1.3 Não houve diferença na distância intercaninos, relação ânteroposterior de caninos decíduos, mordida aberta anterior, tanto nos respiradores bucais e nasais, nos momentos $\mathrm{T} 1$ e $\mathrm{T} 2$.

2. Ao analisar cada grupo separadamente, vinte e oito meses, em média, após o procedimento cirúrgico, foram observadas as seguintes alterações:

- plano terminal dos segundos molares decíduos se modificou de reto para degrau mesial, nos respiradores bucais e nasais

- o overbite sofreu alteração no período avaliado, de negativo para normal nos respiradores bucais e se tornou profundo, nos respiradores nasais

- as distâncias intercaninos e intermolares aumentaram em ambos os grupos 



\section{REFERÊNCIAS}

Agren K, Nordlander B, Linder-Aronson S, Zettergren-Wijk L, Svanborg E. Children with nocturnal upper airway obstruction: postoperative orthodontic and respiratory improvement. Acta Otolaryngol 1998;118:581-587.

Águila, FJ. Manual de cefalometria. São Paulo. Editora Livraria Santos, 1997.

Aragão W. Arago's function regulation. The stomatognatic system and postural changes in children. J Clin Pediatr Dent 1991;15(4):226-30.

Araújo TM. Cefalometria, Conceitos e Análises. Dissertação. Rio de Janeiro: Faculdade de Odontologia - Universidade Federal do Rio de Janeiro, 1983.

Arrarte J, Neto JFL, Fischer GB. The effect of adenotonsillectomy on oxygen saturation in children with sleep breathing disorders. Int J Pediatr Otorhinolaryngol 2007;71:973978.

Arun T, Isik F, Sayinsu K. Vertical growth changes after adenoidectomy. Angle Orthod 2003;73(2):146-150.

Bahadir O, Caylan R, Bektas D, Bahadir A. Effects of adenoidectomy in children with symptoms of adenoidal hypertrophy. Eur Arch Otorhinolaryngol 2006;263:156-159.

Baume LJ. Developmental diagnostic aspects of the primary dentition. Int Dent J 1959;9(3):349-66.

Behlfelt K, Linder-Aronson S, Neander P. Posture of head, the hyoid bone and tongue in children with and without enlarged tonsils. Eur Journal of Orthodontics 1990;12:458467.

Bianchini AP, Guedes ZCF, Vieira MM. Estudo da relação entre respiração oral e o tipo facial. Rev Bras Otorrinolaringol 2007;73(4):500-5.

Bresolin D, Shapiro PA, Shapiro GG, Chapko MK, Dassel D. Mouth breathing in allergic children: It's relationship to dentofacial development. Am J Orthod 1983;83(4):334-9.

Bresolin D, Shapiro GG, Shapiro PA, Dassel SW, Furukawa CT, Pierson WE, Chapko M, Bierman CW. Facial characteristics of children who breathe through the mouth. Pediatrics 1984;73(5):622-25.

Broadbent BH. A new x-ray technique and its application to orthodontia. Angle Orthod 1981;51:93-114.

Brodsky L, Koch JR. Anatomic correlates of normal and diseased adenoids in children. Laryngoscope 1992;102(11):1268-74.

Bruni O. Distúrbios respiratórios do sono em crianças: precisamos acordar para esse problema! Jornal de Pediatria 2008;84(2):101-103.

Btzenberger $D$, Ruf $S$, Pancherz $H$. The compensatory mechanism in high-angle malocclusions: A comparison of subjects in mixed and permanent dentition. Angle Orthod 1999;69(1):27-32. 
Cattoni DM, Fernandes FDM, Di Francesco RC, Latorre MRDO. Características do sistema estomatognático de crianças respiradoras orais: enfoque antroposcópico. PróFono R At Ci 2007;19(4):347-351.

Chang HP, Kinoshita Z, Kawamoto T. A study of growth changes in facial configuration. Eur J Orthod 1993;15(6):493-501.

Chaux R, Klemens C, Patscheider M, Reichel O, Dreher A. Tonsillotomy in the treatment of obstructive sleep apnea syndrome in children: Polysomnographic results. Int J Pediatr Otorhinolaryngol 2008;72:1411-1417.

Cheng M, Enlow DH, Papsedero M, Broabent Jr.BH, Oyen O, Sabat M. Developmental effects of impaired breathing in the face of the growing child. Angle Orthod 1988;58:309-320.

Cohen $D$, Konak S.The evaluation of radiographs of the nasopharynx. Clin Otolaryngol 1985;10(2):73-8.

Cooper BC. Nasorespiratory function and orofacial development. Otorrinolaryngol Clin North Am 1989;22(2):413-41.

Cuccia AM, Lotti M, Caradonna D. Oral Breathing and Head Posture. Angle Orthod 2008;78(1):77-82.

Defabijanis P. Impact of nasal aiway obstruction on dentofacial development and sleep disturbances in children: preliminare notes. J Clin Pediatric Dent 2003;27(2):95-100.

Di Francesco RC. Respirador bucal: visão do otorrinolaringologista. JBO 1999;12(4):241-247.

Diamond O. Tonsils and adenoids: why the dilemma? Am J Orthod 1980;78(5):495503.

Faria PTM. Aspectos esqueléticos e dentários de pacientes portadores de respiração bucal. 2000. 66f. Monografia (Especialização em Ortodontia e Ortopedia Facial.) Escola de Farmácia e Odontologia de Alfenas, Alfenas.

Fields HW, Warren DW, Black K, Phillips CL. Relationship between vertical dentofacial morphology and respiration in adolescents. Am J Orthod 1991;99(2):147-54.

Forsberg CM, Krekmanova L, Dahllöf G. The effect of growth hormone therapy on mandibular and cranial base development in children treated with total body irradiation. Eur J Orthod 2002;24:285-292.

Fujioka M, Young LW, Girdany BR. Radiographic evaluation of adenoidal size in children: adenoidal-nasopharyngeal ratio. Am J Roentgenol 1979;133(3):401-4.

Góis EGO, Ribeiro-Júnior HC, Vale MPP, Paiva SM, Serra-Negra JMC, Ramos-Jorge ML, Pordeus IA. Influence of Nonnutritive Sucking Habits, Breathing Pattern and Adenoid Size on the Development of Malocclusion. Angle Orthod 2008;78(4):647-54. 
Greenfeld M, Tauman R, DeRowe A, Sivan Y. Obstructive sleep apnea syndrome due to adenotonsillar hypertrophy in infants. Int J Pediatr Otorhinolaryngol 2003;67:10551060.

Gross AM, Kellum GD, Michas C, Franz D, Foster M, Walker M, Bishop FW. Open mouth posture and maxillary arch width in young children: a three years evaluation. Am J Dentofacial Orthop 1994;106(6):635-40.

Guileminault C, Li K, Quo S, Inouye RN. A prospective study on the surgical outcomes of children with sleep-disorders breathing. Sleep 2004;27(1):95-100.

Haiter-Neto F, Oliveira SS, Casanova MS, Caldas MP. Telerradiografias obtidas em posição natural da cabeça alteram as grandezas cefalométricas? Dental Press Ortodon Ortop Facial 2007;12(4):117-123.

Hartgerink DV, Vig PS. Lower anterior facial height and lip incompetence do not predict nasal airway obstruction. Angle Orthod 1989;59(1):17-23.

Hiyama S, Ono T, Ishiwata $Y$, Kuroda T, Ohyama K. Effects of experimental nasal obstruction on human masseter and suprahyoid muscle activities during sleep. Angle Orthod 2003;73(2):151-7.

Honda LO. Estudo cefalométrico radiográfico comparativo das características dentoesquelético-faciais de crianças Brasileiras, na faixa etária de 3 a 6 anos de idade, portadoras de dentaduras decíduas normais, com maloclusão de Classe II e com maloclusão de Classe III. Dissertação. São Paulo: Faculdade de Odontologia da Universidade de São Paulo, 1997. (Doutorado em Odontologia)

Hulcrantz E, Larson M, Hellquist R, Ahlquist-Astad J, Svanholm H, Jakobson OP. The influence of tonsillar obstruction and tonsillectomy on facial growth and dental arch morphology. Int J Pediatr Otorhinolaryngol 1991;22(2):125-34.

Jabur LB, Macedo AM, Cravero LH, Nunes MM. Estudo clínico da correlação entre padrão respiratório e alterações ortodônticas e miofuncionais. Rev Odontol Unicid 1997;9(2):105-117.

Joseph R. The effect of airway interference on the growth and development of the face, jaws and dentition. Int J Oral Myol 1982;8:4-9.

Junqueira PAS, Di Francesco RC, Trezza P, Zeratti P, Frizzarini R, Faria MEJ. Alterações funcionais do sistema estomatognático pré e pós-adenoamigdalectomia. Pro Fono Revista de Atualização Científica 2002;14(1):17-22.

Kawashima S, Peltomäki T, Sakata H, Mori K, Happonen RP, Rönning O. Craniofacial morphology in preschool children with sleep-related breathing disorder and hypertrophy of tonsils. Acta Paediatrica 2002;91:71-77.

Kerr WJS, McWilliam JS, Linder-Aronson S. Mandibular form and position related to changed mode of breathing-a five-year longitudinal study. Angle Orthod 1987;59(2):91-96.

Klein JC. Nasal respiratory function and craniofacial growth. Arch Otolaryngol Head Neck Surg 1986;112(8):843-49. 
Kluemper GT, Vig PS, Vig KWL. Nasorespiratory characteristics and craniofacial morphology. Eur J Orthod 1995;17:491-95.

Lee SHMD, Choi JHMD, Shin CMD, Lee HMMD, Kwon SYMD. Laryngoscope 2007;117(6):1102-1106.

Lessa FCR, Enoki C, Feres MFN, Valera FCP, Anselmo-Lima WT, Matsumoto MAN. Influência do padrão respiratório na morfologia craniofacial. Rev Bras Otorrinolaringol $2005 ; 71(2): 156-60$.

Lima AASJ, Köhler GI, Petrelli E. Estudo Cefalométrico e Nasofibroscópico das Características Craniofaciais e oclusais em pacientes com obstrução das vias aéreas superiores. J Bras Ortodon Ortop Facial 2005;10(55):37-48.

Linder-Aronson S. Adenoids: their effect on the mode of breathing and nasal airflow and their relationship to characteristics of the facial skeleton and the dentition. Acta Oto-laryng. Suppl 1970;265:5-132.

Linder-Aronson S. Effects of adenoidectomy on dentition and nasopharynx. Am J Orthod 1974;65(1):1-15.

Linder-Aronson S. Respiratory function in relation to facial morphology and dentition. $\mathrm{Br}$ J Orthod 1979;6(2):59-71.

Linder-Aronson S, Woodside DG, Lundströn A. Mandibular growth direction following adenoidectomy. Am J Orthod 1986;89(4):273-84.

Linder-Aronson S, Woodside DG, Hellsing E, Emerson W. Normalization of incisor position after adenoidectomy. Am J Orthod Dentofacial Orthop 1993;103(5):412-27.

McDonald RE, Avery DR. Odontopediatria. Supervisão da Trad. de Roberval de Almeida Cruz. 6a.ed. Rio de Janeiro: Guanabara-Koogan, 1995.

McNamara JAJr. Influence of respiratory pattern on craniofacial growth. Angle Orthod 1981;51(4):269-300.

Melsen B, Attina L, Santuari M, Attina A. Relationships between swallowing pattern, mode of respiration, and development of malocclusion. Angle Orthod 1987;57:133-20.

Mocellin M, Fugman EA, Gavazzoni FB, Ataíde AL, Ouriques FL, Herrero JF. Estudo cefalométrico-radiográfico e otorrinolaringológico correlacionado com o grau de obstrução nasal e o padrão de crescimento facial em pacientes não tratados ortodonticamente. Disponível em:

http://www.sborl.com.br/revista662/html/body materia4.htm. Acesso em: 05 jun.2000.

Moffatt JB. Habits and their relation to malocclusion. Aust Dent J 1963;8(2):142-9.

Monteiro ECM, Pilon RR, Dall'Oglio GP. Estudo da Hipertrofia Adenoideana: Endoscopia $X$ Radiografia de Nasofaringe. Rev Bras Otorrinolaringol 2000;66(1):9-12.

Moreira M. Evaluation of palatal depth and width in mouth breathers with primary dentition. J Orofacial Myol 1989;15(1):19-24. 
Motonaga SM, Berte LC, Anselmo-Lima WT. Respiração bucal: causas e alterações no sistema estomatognático. Rev Bras Otorrinolaringol 2000;66(4):373-9.

Nanda RS. The rates of growth of several facial components measured from serial cephalometric roentgenograms. Am J Orthod 1955;41(9):658-673.

Nowak AJ, Warren JJ. Infant oral health and oral habits. Pediatr Clin North Am 2000;47(5):1043-66.

O'ryan FS, Gallagher DM, Lablanc JP, Epker BN. The relation between nasorespiratory function and dentofacial morphology: a review. Am J Orthod 1982;82(5):403-10.

Oulis CJ, Vadiakas GP, Ekonomides J, Dratsa J. The effect of hypertrophic adenoids and tonsils on the development of posterior crossbite and oral habits. J Clin Pediatr Dent 1994;18(3):197-201.

Paul JL, Nanda RS. Effect of mouth breathing on dental occlusion. Angle Orthod 1973;43(2):201-206.

Peltomäki T. The effect of mode of breathing on craniofacial growth-revisited. Eur J Orthod 2007;29(5):426-9.

Principato J]. Upper airway obstruction and craniofacial morphology. Otolaryngol Head Neck Surg 1991;104(6):881-90.

Ribeiro EC, Marchiori SC, Silva AMT. Electomiographic Muscle EMG Activity in Mouth and Nasal Breathing Children.The Journal of Craniomandibular Practice 2004;22(2):145-150.

Ricketts RM. Cephalometric analysis and synthesis. Angle Orthod 1961;31(3):141-56.

Ricketts RM. Respiratory obstruction syndrome. Am J Orthod 1968;54(7):495-507.

Sabatoski CV, Maruo H, Camargo ES, Oliveira JHG. Estudo comparativo de dimensões craniofaciais verticais e horizontais entre crianças respiradoras bucais e nasais. J Bras Ortodon Ortop Facial 2002;7(39):246-257.

Santos-Pinto CCM, Henriques JFC, Pinzan A, Freitas MR, Santos-Pinto A. Estudo radiográfico e de modelos, para avaliação de alterações dentofaciais em função da redução do espaço nasofaríngeo em jovens brasileiros leucodermas de 8 a 14 anos de idade. Ortodontia 1993;26(2):57-74.

Sassouni $\mathrm{V}$, Shnorhokian $\mathrm{H}$, Beery Q. Influence of perennial allergic rhinits (PAR) on facial type, abstracted. J Allergy Clin Immunol 1982;69(2):149.

Scheideman GB, Bell WH, Legan HL, Finn RA, Reisch JS. Cephalometric analysis of dentofacial normals. Am J Orthod 1980;78(4):404-420.

Schendel SA, Eisenfeld J, Bell WH, Epker NB, Mishelevich DJ. The long face syndrome: Vertical maxillary excess. Am J Orthod 1976;70(4):398-408.

Smith RM, Gonzales C. The relationship between nasal obstruction and craniofacial growth. Pediatr Clin North Am 1989;36(6):1432-34. 
Sousa JBR, Anselmo-Lima WT, Valera FCP, Gallego AJ, Matsumoto MNA. Cephalometric assessement to the mandibular growth pattern in mouth-breathing children. Int J Pediatr Otorhinolaryngol 2005;69:311-317.

Subtelny JD. Effects of diseases of tonsils and adenoids on dentofacial morphology. Ann Otol Rhinol Laryngol. Supplement 19 1975;84(2):50-4.

Subtelny JD. Oral Respiration: facial maldevelopment and corretive dentofacial orthopedics. Angle Orthod 1980;50(3):147-64.

Tourné LPM. Growth of the pharynx and its physiologic implications. Am J Dentofac Orthop 1991;99(2):129-39.

Tourné LPM, Schweiger J. Immediate postural responses to total nasal obstruction. Am J Dentofac Orthop 1996;110(6):606-11.

Trask GM, Shapiro PA. The effect of perennial allergic rhinitis on dental and skeletal development: a comparison of sibling pairs. Am J Orthod Dentofac Orthop 1987;92(4):286-93.

Trotman CA, Macnamara JrJA, Dibbetts JMH, Van Der Weele LT. Association of lip posture and dimensions of the tonsils and sagittal airway with facial morphology. Angle Orthod 1997;67(6):425-32.

Ung N, Koenig J, Shapiro PA, Shapiro G, Trask G. A quantitative assessment of respiratory patterns and their effects on dentofacial development. Am J Dentofac Orthop 1990;98(6):523-32.

Unkel C, Lehnerdt G, Schmitz KJ, Jahnke K. Laser-tonsilotomy for treatment of obstructive tonsilar hiperplasia in early childhood: a retrospective review. Int J Pediatr Otorhinolaryngol 2005;69(12):1615-20.

Valera FCP, Travitzki LVV, Mattar SEM, Matsumoto MAN, Anselmo-Lima WT. Muscular, functional and orthodontic changes in pre school children with enlarged adenoids and tonsils. Int. J. Pediatr. Otorhinolaryngol 2003;67:761-770.

Valera FCP, Trawitzki LVV, Anselmo-Lima WT. Myofuncional evaluation after surgery for tonsils hypertrophy and its correlation to breathing pattern: a 2 years-follow up. Int J Pediatr Otorhinolaryngol 2006;70:221-225.

Vig PS, Sarver DM, Hall DJ, Warren DW. Quantitative evaluation of nasal airflow in relation to facial morphology. Am J Orthod 1981;79(3):263-72.

Vilella OV. Manual de Cefalometria. Koogan. Rio de Janeiro; 1998.

Warren DW. Effect of airway obstruction upon facial growth. Otolaryngol Clin North America 1990;23(4):699-712.

Weider DJ, Baker GL, Salvatoriello FW. Dental malocclusion and upper airway obstruction, an otolaryngologist's perspective. Int J Pediatr Otorhinolaryngol 2003;67:323-331. 
Woodside DG, Linder-Aronson S, Lundstrom A, Mcwillian J. Mandibular and maxillary growth after changed mode of breathing. Am J Dentofacial Orthop 1991;100(1):1-18.

Wormald PJ, Prescott CAJ. Adenoids: comparison of radiological assessment methods with clinical and endoscopic findings. J Laryngol Otol 1992;106:342-44.

Wylie WL, Johnson EL. Rapid evaluation of facial dysplasia in vertical plane. Angle Orthod 1952;22(3):165-182.

Yi LC, Guedes ZCF, Pignatori S, Weckx LLM. Avaliação postural em crianças de 5 a 12 anos que apresentam respiração oral. Fisioterapia em movimento 2003;16(3):29-33.

Zettergren-Wijk L, Forsberg CM, Linder-Aronson S. Changes in dentofacial morphology after adeno-/tonsillectomy in young children with obstructive sleep apnoea - a 5-year follow-up study. Eur J Orthod 2006;28:319-326.

Zucconi M, Caprioglio A, Calori G, Ferini-Strambi L, Oldani A, Castronovo C, Smirne S. Craniofacial modifications in children with habitual snoring and obstructive sleep apnoea: a case-control study. Eur Respir J 1999;13:411-417. 



\title{
Anexo I
}

\author{
UNIVERSIDADE DE SÃO PAULO \\ FACULDADE DE ODONTOLOGIA DE RIBEIRÃO PRETO
} Of.CEP/064/FORP/080403

Senhora Professora,

Ref. Processo n० 2000.1.483.58.5

De ordem do Senhor Coordenador do Comitê de Ética em Pesquisa, desta Faculdade, informamos que o referida Comitê, em sua 43 a Sessão, realizada no dia 04 de abril de 2003, deliberou aprovar o Relatório Final do Projeto de Pesquisa envolvendo seres humanos intitulado: "Avaliação do padrão funcional e do crescimento facial em crianças respiradoras bucais".

Solicitamos que quando da publicação do trabalho, seja encaminhada uma fotocópia à Secretaria do Comitê de Ética em Pesquisa, desta Faculdade.

Atenciosamente,

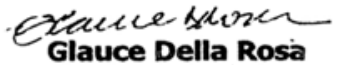

Secretária do Comitê de Ética em Pesquisa

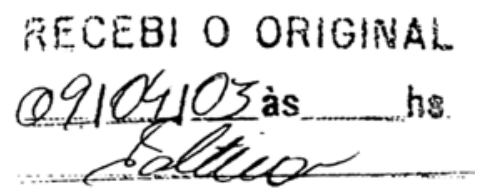

Ilma. Sra.

Profa. Dra. MÍrian AIKo NAKANE MATSUMOTO

Professora Doutora do Depe'tamento de Clínica Infantil, Odontologia Preventiva e Social

GDR/gdr 


\section{ANEXO II}

\section{TERMO DE CONSENTIMENTO}

$\mathrm{Eu}$, responsável pelo menor paciente atendido na Clínica de Ortodontia Preventiva e/ou Odontopediatria da Faculdade de Odontologia de Ribeirão Preto - USP, fui devidamente esclarecido (oral e por escrito) pelo(a) que:

- O profissional realizará moldagens das arcadas dentárias superior e inferior dos pacientes para obtenção dos modelos de estudo em gesso.

- Os pacientes serão radiografados para obtenção de radiografia lateral da cabeça, que será utilizada para avaliação do crescimento e do padrão facial.

- As tomadas radiográficas serão realizadas de acordo com normas preconizadas, indicada para cada paciente.

- Os pacientes serão submetidos à avaliação médica e fonoaudiológica no Ambulatório de Otorrinolaringologia do Hospital das Clínicas da Faculdade de Medicina de Ribeirão Preto USP para verificar se a criança possui respiração bucal. Se a respiração bucal for constatada, o paciente receberá o tratamento médico adequado no referido Ambulatório do Hospital das Clínicas.

- Em seguida ao tratamento, o paciente será acompanhado para avaliação do desenvolvimento das suas arcadas dentárias podendo ser encaminhado, se necessário, para atendimento na Clínica de Ortodontia Preventiva .

- Tenho plena liberdade de recusar que o menor, sob minha responsabilidade participe desta pesquisa, assim como tenho a liberdade de retirá-lo desta pesquisa, em qualquer momento, sem penalização alguma e sem prejuízo do atendimento.

- Foi-me assegurado o sigilo da minha privacidade.

- Não me é previsto indenização ou ressarcimento de despesas, já que a conduta dos procedimentos não é experimental, nem agressiva à saúde física e moral.

Estou ciente que esta pesquisa tem como responsáveis a $\operatorname{Prof}^{a}$. Dr ${ }^{a}$. Mírian A . N. Matsumoto e a cirurgiã- dentista Sara Elisa Medina Mattar.

Assino este documento de livre e espontânea vontade, estando ciente do seu conteúdo.

Ribeirão Preto, / ～～～～

Responsável pelo paciente

Prof $^{a} \cdot$ Dr $^{a}$. Mirian Matsumoto

C.D. Sara Elisa Mattar 


\section{ANEXO III \\ TRABALHO DE CEFALOMETRIA EM HAVA}

Nome:

REG: idade:

\section{História:}

Roncos I RBS I̊ obstrução nasal l hipersalivação noturna Apnéias: freqüentes I ocasionais I̊ ausentes l̊

Infecções de Repetição: amigdalites li sinusites l otites l

Prurido nasal Î rinorréia I espirros

\section{Medicamentos usados:}

Hábitos: chupeta I mamadeira I

dedol bruxismo I̊

Alimentação: sólida I pastosa Î líquidal

Carne: tudo İ só moída/ chupa İ não come I̊

\section{Exame:}

\section{Olheiras $\square$ hipoplasia maxilar $\square$ ombros caídos $\square$}

Otoscopia:

Rino Anterior: CCII normocorados I pálidos I hiperemiados I̊

CCII normotróficos 1 hipertrofiados 1

Oroscopia: amígdalas Grau: I I II I III İ IV i̊

Palato: normal I̊ ogival l̊

Úvula:

RX: Cohen e Konak (coluna aérea/palato mole):

\section{Cirurgia:}

Data: 
Anexo IV

FICHA DE PESQUISA

n- __ data referência

\section{1- Identificação}

Nome:

Sexo:

D.N.:

Idade atual:

Endereço: Bairro:

Cidade: Tel: Tel recado:

End. referência:

Pai:

Profissão:

Trabalho: Tel:

Mãe:

Profissão:

Trabalho:

Tel:

Encaminhado por:

Em atendimento na clínica: $n$. prontuário aluno resp.: 
Informações adicionais:

2-História médica do paciente:

geral

respiratória

traumatismos dentários

face

história dental

4- Exame Bucal e Funcional

saúde bucal atual : $\quad($ ) boa $\quad($ ) regular $\quad(\quad)$ má

higiene bucal atual : ( ) boa ( ) regular ( ) má

cárie nos dentes:

5-Bruxismo

( )presente ( )diurno ( )noturno

( )ausente 